\title{
BOICOT CONTRA MEXICANOS: EL MOVIMIENTO ANTICHINO EN CHIHUAHUA
}

\author{
José Gamboa García \\ Universidad Autónoma de Chibuabua
}

INTRODUCCIÓN

Tas actividades antichinas en México han merecido la aten_ción de los historiadores, sobre todo el caso de Sonora, que fue el más exitoso para la causa xenofóbica. Se han hecho aportaciones sobre lo acontecido en otros estados y también sobre el antichinismo a nivel nacional, pero el caso de Chihuahua no ha recibido mucha atención. La población china censada en este estado en 1930 fue de 884, ocupando así el sexto lugar con $5.5 \%$. En comparación con otras entidades del norte del país, en Chihuahua los antichinos parecen haber logrado menos éxito. La población china censada de este estado, de 1930 a 1940, disminuyó $41 \%$, porcentaje mucho menor a $97 \%$ de Sonora, a $90 \%$ de Sinaloa, a $80 \%$ que se dio en la Baja California y también menor a $55 \%$ que se presentó en Coahuila. ${ }^{1}$

Fecha de recepción: 22 de junio de 2019

Fecha de aceptación: 22 de enero de 2020

${ }^{1}$ Cálculos propios a partir de los datos de Ham, "La migración china hacia México”, p. 180. En Tabulados del Sexto Censo de Población, publicado por el 
Aunque se han documentado declaraciones de nacionales que condenaron los malos tratos infligidos a los chinos, ${ }^{2}$ poco se ha atendido el papel desempeñado por mexicanos que públicamente se enfrentaron a acciones sinofóbicas. En Chihuahua, opositores a las actividades antichinas defendieron aguerridamente su derecho a continuar sus relaciones comerciales con chinos. Por su parte, como en el resto del país, los sinófobos se autodefinieron como nacionalistas, y esto se ha aceptado en la historiografía. No obstante, chihuahuenses que se manifestaron en contra de los ataques antichinos igualmente se asumían como nacionalistas: tanto éstos como los sinófobos apelaban a las raíces españolas e indígenas para fundamentar la "superioridad" racial de los mexicanos y estaban en contra de la miscegenación con los chinos. Sin embargo, como ha argumentado Morris, mientras que algunos nacionalistas pueden percibir algo como amenaza, otros bien pueden considerarlo como provechoso para la nación. ${ }^{3}$ El caso de Chihuahua muestra que el nacionalismo mestizofílico posrevolucionario también podía manifestarse como tolerancia y condescendencia, beneficiando a mexicanos con las ventajas económicas de la presencia china y preocupándose además por tratar bien a los extranjeros para dar una buena imagen de México a nivel internacional.

A continuación se abordan conflictos en torno de la presencia china en Chihuahua. Primero, se menciona de forma sucinta su llegada al estado, para luego seguir con la fase armada de la revolución mexicana, durante la cual los chinos en Chihuahua fueron víctimas de saqueos y asesinatos. Se continúa con el hostigamiento más institucional que padecieron al terminar

\footnotetext{
INEGI, se muestra que en 1940 en el estado de Chihuahua había 206 personas que habían cambiado su nacionalidad china a mexicana. Solo el Distrito Federal, con 230, tenía una mayor cantidad, https://www.inegi.org.mx/programas/ ccpv/1940/default.html\#Tabulados. Consultado el 20 de febrero de 2019.

2 Schiavone Camacho, Chinese Mexicans, p. 75.

3 Morris, "Reforming the Nation", p. 367.
} 
la guerra, y la respuesta de chinos, autoridades y prensa a las actividades sinofóbicas. Se prosigue con el boicot que puso de manifiesto las distintas posturas que grupos de chihuahuenses tomaron respecto de chinos y antichinos, las cuales estuvieron permeadas por intereses económicos y argumentos de tipo nacionalista. Finalmente, se presentan las conclusiones.

\section{LA LLEGADA DE LOS CHINOS A CHIHUAHUA}

Alrededor de 1864, unos pocos chinos se trasladaron de Estados Unidos a México. Trabajaron en los ferrocarriles que conectaban El Paso, Texas, con la ciudad de México. Se asentaron en la ciudad de México, Tampico, Mexicali, Monterrey y Chihuahua, y en su mayoría se dedicaban a la agricultura, industria y comercio pequeños. ${ }^{4}$ En 1871, el gobierno mexicano oficialmente buscó la inmigración china, aunque no sin despertar oposición. ${ }^{5}$ Algunos arribaron al norte del país luego de que los Estados Unidos de América prohibieron la entrada de trabajadores de tal nacionalidad en 1882 por medio del Acta de Exclusión. ${ }^{6}$ En 1884, había algunos centenares en el norte de México; ${ }^{7}$ varias decenas de ellos residían en Chihuahua. ${ }^{8}$ Para 1893, había colonias chinas en el territorio de Baja California y en los estados de Sonora, Sinaloa, Coahuila, Tamaulipas y también en Chihuahua. ${ }^{9}$ En 1899 se signó el Tratado de Amistad y Comercio entre México y China, con lo cual aumentó su inmigración. ${ }^{10}$ Para 1904, 45\% estaba avecindado en Sonora, teniendo los estados

\footnotetext{
${ }^{4} \mathrm{Wu}$, Chinos en México y Guatemala, en CHOU, Los chinos en Hispanoamérica, p. 13.

5 Botton, "La persecución de los chinos en México", pp. 479-480.

${ }^{6}$ Schiavone Camacho, "Crossing Boundaries", p. 549.

7 González Navarro, Los extranjeros en México, vol. in, p. 167.

${ }^{8}$ Ham, "La migración china hacia México", p. 180.

9 Hu DeHart, “Immigrants to a Developing Society", pp. 275-312.

10 Romero, The Chinese in Mexico, p. 27.
} 
de Chihuahua, Coahuila, y Sinaloa más de 5\% cada uno. La mayoría de los chinos llegaron como trabajadores. Con frecuencia, acumulaban pequeños capitales que les permitían la venta ambulante de frutas y vegetales o establecer lavanderías, hoteles, restaurantes o tiendas. ${ }^{11}$ Fue el caso del noroeste de Chihuahua. En 1909, en Nuevo Casas Grandes habían establecido fondas, pequeñas tiendas y dos de los principales hoteles del estado. En 1910, eran seis los negocios de estos extranjeros registrados en Casas Grandes. Las inversiones del empresario canadiense Pearson atrajeron a los chinos: se les encontraba en las minas de la Candelaria Mining Co., así como en Estación Pearson. ${ }^{12}$ En esta localidad, como en otros aserraderos, también había lavanderías, fondas y otros comercios chinos y su clientela estaba formada sobre todo por trabajadores. ${ }^{13}$

\section{ACCIONES ANTICHINAS DURANTE LA FASE ARMADA}

DE LA REVOLUCIÓN EN CHIHUAHUA

Como en otras partes, durante la revolución mexicana los chinos fueron objeto de acciones violentas, habiendo gran cantidad de reclamaciones al respecto.$^{14}$ En la localidad de Pedernales, en diciembre de 1910, Francisco Villa y algunos de sus hombres extorsionaron, golpearon y robaron a un chino. ${ }^{15} \mathrm{En}$ septiembre de 1911, en la comunidad Pratt, cerca de la colonia mormona Dublán, unos bandoleros incendiaron la casa de unos chinos: robaron 100 pesos y al huir estos extranjeros, los asesinaron a puñaladas. ${ }^{16}$ En 1912, durante meses comerciantes

\footnotetext{
11 Cотт, “Mexican Diplomacy and the Chinese Issue”, pp. 70 y 79.

12 Lloyd, El proceso de modernización capitalista, p. 124.

13 LLoyd, Cinco ensayos sobre cultura material, pp. 113-114.

14 Romero, The Chinese in Mexico, p. 148.

15 “'No prisoners' is Navarro's order”, Los Angeles Herald (15 dic. 1910).

16 "Mexicans rob and burn at Dublan”, El Paso Herald (28 sep. 1911); "Mexicans burn and raid Chinese Home”, The San Francisco Call (29 sep. 1911).
} 
chinos de Ciudad Juárez fueron agredidos y víctimas de despojos. ${ }^{17}$ En julio de 1913, la legación china solicitó a la Cruz Roja que se socorriera a 150 chinos en Estación Pearson. El secretario de Estado de Estados Unidos envió un telegrama al cónsul de su país en Ciudad Juárez ordenándole que investigara las condiciones de los chinos, sus necesidades de alimentación y alojamiento, así como la forma de obtener alimentos y de auxiliar a los chinos de la manera más ágil posible. No obstante, el mensaje del secretario tardó en llegar a su destinatario. ${ }^{18}$ Por indicación del cónsul chino de San Francisco, California, Mar Wing Kee, el representante consular en El Paso, Tejas, Li Yeung Keo, debía investigar el asesinato del encargado de un restaurante en la estación ferroviaria de Pearson, Wong Chew, a manos de tropas al mando de Máximo Castillo. Además, debía recomendar a los chinos de la región oeste del estado que abandonaran la zona y se fueran cerca de la frontera. Un mensajero de la Madera Lumber Company fue encargado de llevar el recado: alrededor de un centenar de chinos trabajaban en campos madereros y ferroviarios de la zona ${ }^{19}$ y se temía una masacre..$^{20}$ Junto con un grupo de estadounidenses, 75 chinos de la región de Madera huyeron a la ciudad de Chihuahua. ${ }^{21}$ El gobierno de Estados Unidos les había autorizado ingresar al país. ${ }^{22}$ Después de dos semanas en la capital del estado, el día

17 Treviño, “Los 'hijos del cielo' en el infierno", p. 434.

18 DSUSA, OH, PRFRUS, APC, exp. 312.93/37, https://history.state.gov/ historicaldocuments/frus1913/d1192. Consultado el 15 de marzo de 2019.

19 "General Villa Orders Troops to Concentrate for Attack on Juárez", Salt Lake City Herald (30 jul. 1913).

20 “Are Creeping upon Juarez", Daily Gate City (30 jul. 1913).

21 "Nine Trains Start South under Guard of 2000 Federales", Salt Lake Herald (25 ago. 1913).

22 "Edmond Hayes Jr., American, Killed by Bandit at Madera", Salt Lake Herald (26 ago. 1913). 
29 de agosto arribaron a El Paso. ${ }^{23}$ Fueron 39 los que llegaron a la línea fronteriza. ${ }^{24}$

En su "Manifiesto a la Nación", en 1914 Francisco Villa prohibió a los chinos y a los estadounidenses la propiedad de bienes raíces. El Manifiesto explicaba los motivos para privar de ese derecho a los estadounidenses pero no daba razón alguna para el caso de los chinos. ${ }^{25}$ En marzo de 1915, Villa ordenó a sus comandantes que evitaran atacar a los chinos de Chihuahua: eran necesarios para abastecer a la población y evitar que el hambre la llevara a la desesperación. ${ }^{26}$ No obstante, en octubre del mismo año, en Santa Rosalía (hoy Camargo), el general villista Baudelio Uribe ordenó la ejecución de chinos y árabes. ${ }^{27}$ En febrero de 1916, huestes carrancistas asesinaron al chino Charley Chee, dueño de un hotel en Jiménez. ${ }^{28}$ Los soldados sacaron del hotel y llevaron a la maleza a un ciudadano estadounidense y a Chee, pero sólo ejecutaron a este último: el general Prieto había dado la orden..$^{29}$ En abril del mismo año, soldados villistas saquearon tiendas chinas en San Isidro de las Cuevas (hoy Villa Matamoros). Luego, habitantes de la localidad también sustrajeron mercancías. El general Ernesto García ordenó que los artículos robados fueran depositados en la presidencia municipal para su devolución a sus propietarios, pero el militar se marchó a seguir su campaña y sus órdenes no fueron obedecidas. Los afectados dirigieron su queja a la representación china. ${ }^{30}$ Para noviembre

\footnotetext{
23 "Refugees Reach El Paso Safely", Ogden Daily Standard (29 ago. 1913). 24 "Madera Refugees Arrive at El Paso; Are without Funds", Salt Lake Herald, (30 ago. 1913).

${ }_{25}$ Delgado, Romance histórico villista, p. 176.

${ }^{26}$ Chang, Chino, p. 114.

27 “American Killed by Villa Bandits", Sausalito News, vol. 32, núm. 46 (11 nov. 1916).

${ }^{28}$ KIm, "Immigrants, Workers, Pioneers", p. 124; Chang, Chino, p. 113.

29 Chang, Chino, p. 113.

30 AHMHP, E, c. 6, exp. 9, documento sin foliación.
} 
de 1916, más de 200 chinos habían huido a El Paso, Tejas. ${ }^{31}$ En ese mismo mes, un comerciante chino informó que villistas habían asesinado a todos los extranjeros de Hidalgo del Parral, incluyendo a por lo menos 20 chinos, ${ }^{32}$ aunque la cifra pudo haber llegado a $80 .{ }^{33}$ Otros refugiados afirmaron que habían sido más de 200 los chinos ejecutados entre Parral y Jiménez, aseverando que, además, dos mujeres casadas con chinos fueron quemadas vivas junto con sus hijos. ${ }^{34}$ Por lo menos desde octubre de 1916 Villa había dado la orden de "quemar vivas a las que se anden pisando con chinos", pero dicha orden se cumplía de forma caprichosa. ${ }^{35}$

El día 20 de noviembre de ese mismo año de 1916, los "principales" chinos de la ciudad de Chihuahua acudieron con el cónsul alemán para pedirle que solicitara al general Treviño, encargado de la plaza, que les facilitara un tren custodiado a Ciudad Juárez. El representante chino en dicha localidad fronteriza les había telegrafiado indicándoles que se desplazaran a Ciudad Juárez, pues Villa atacaría la ciudad y habría una masacre de chinos. El general respondió que, aunque podría disponer del tren, no había necesidad del mismo, pues él defendería la plaza. En vista de la respuesta, el cónsul alemán ofreció su protección a los chinos. Sin embargo, al atacar los villistas, los chinos no encontraron al cónsul. Antes del 29 de noviembre, ya habían saqueado los comercios del barrio chino y asesinado a culatazos y con garrotes a 26 de sus 27 habitantes. Otros 35 fueron asesinados en las afueras de la ciudad. El día 30 de noviembre llegaron 40 chinos a El Paso, Tejas. Otros 14 que caminaban junto a la vía

\footnotetext{
31 Chang, Chino, p. 114.

32 "Report Foreigners Killed by Bandits", The Sacramento Union (19 nov. 1916); “6 Americans Killed by Villa at Parral”, Sausalito News (25 nov. 1916). 33 "Villa expected to capture Torreon again", San Bernardino Daily Sun (22 dic. 1916).

34 “American Killed by Villa Band”, The Sacramento Union (20 nov. 1916).

35 Brondo, Sucesos notables, p. 109.
} 
no abordaron el tren pues la tripulación no se los permitió por estar sobrecargado. ${ }^{36}$ Para el 10 de diciembre, 300 de un total de 1000 chinos que habitaban la capital del estado, habían llegado a Ciudad Juárez. ${ }^{37} \mathrm{Al}$ parecer, en diciembre, la masacre continuó tanto en la ciudad ${ }^{38}$ como en sus alrededores. Sólo unos cuantos escaparon. ${ }^{39}$ Las víctimas por lo menos sumaron decenas ${ }^{40} \mathrm{y}$ tal vez alcanzaron varios centenares. ${ }^{41}$ Aparentemente, en la Plaza Hidalgo de esa ciudad, Francisco Villa había pronunciado un discurso xenofóbico. ${ }^{42}$ Tres testigos chinos afirmaron que Villa había dado la orden de exterminar a todos los chinos. ${ }^{43}$

En febrero de 1919, villistas bajo las órdenes de Ramón Vega, en Estación Pearson, saquearon la tienda de la Madera Lumber Company y también mercancía con valor de varios miles de pesos del comercio de un chino, a quien asesinaron; ${ }^{44}$ otros dos de sus connacionales murieron a manos de las huestes de

${ }^{36}$ DSUSA, OH, PRFRUS, APC, exp. 812.00/20044, https://history.state.gov/ historicaldocuments/frus1916/pg_617. Consultado el 15 de marzo de 2019. 37 DSUSA, OH, PRFRUS, APC, exp. 812.00/20044, https://history.state.gov/ historicaldocuments/frus1916/pg_617 y https://history.state.gov/historicaldocuments/frus1916/pg_618. Consultado el 15 de marzo de 2019.

38 "Carranza Forces to Attempt Recapture of Chihuahua City", The Daytona Daily Nerws (2 dic. 1916); " 80 Chinese murdered at Chihuahua by Villa", Red Bluff Daily Nerws (3 dic. 1916).

${ }^{39}$ KIM, "Immigrants, Workers, Pioneers", pp. 123-124.

${ }^{40}$ KIM, "Immigrants, Workers, Pioneers", pp. 123-124; Delgado, Making the Chinese Mexican, p. 130; DSUSA, OH, PRFRUS, APC, 812.00/20044, https://history.state.gov/historicaldocuments/frus1916/pg_617 y https:// history.state.gov/historicaldocuments/frus1916/pg_618. Consultado el 15 de marzo de 2019.

${ }_{41}$ "Residents flee as Juarez arms to fight Villa", The Washington Herald (2 dic. 1916).

${ }^{42}$ "Villa Bandits Pillage Chihuahua", The Nerw York Times (2 dic. 1916).

${ }^{43}$ DSUSA, OH, PRFRUS, APC, exp. 812.00/20044, https://history.state.gov/ historicaldocuments/frus1916/pg_618. Consultado el 15 de marzo de 2019. 44 "Villa Followers Loot Mexican Town", The Sacramento Union (9 feb. 1919). 
Vega. ${ }^{45}$ Según Jason Chang, cuando las condiciones económicas empeoraban, era importante cuidar de los comerciantes chinos, pero una situación militar adversa llevaba a permitir que los atacaran. ${ }^{46}$

\section{TRAS LA FASE ARMADA}

Luego de la fase armada, las acciones contra los chinos se encaminaron a cauces más institucionales. En mayo de 1919, en Ciudad Juárez, aparecieron en las paredes carteles en los que se acusaba a los chinos de haber cometido crímenes; el texto estaba fechado en Magdalena, Sonora. ${ }^{47}$ El líder chino Chew Look pidió ayuda al cónsul de Estados Unidos, quien se comunicó con las autoridades de la ciudad, las cuales aseguraron a los chinos que se les protegería. ${ }^{48}$ En agosto de 1924, como respuesta a una circular de su homólogo de Nogales, Sonora, el ayuntamiento de Ciudad Juárez señaló que ya se había dirigido a la Secretaría de Relaciones Exteriores para denunciar que, al darles la ciudadanía mexicana a chinos "que estaban invadiendo esta región”, se perjudicaba a los nacionales. El ayuntamiento juarense acordó dirigirse al Congreso del estado para solicitar que se modificara el tratado entre México y China. ${ }^{49}$

El día 29 de enero de 1925, los comercios chinos de la ciudad de Chihuahua fueron inspeccionados por la policía local, de una forma que el periódico El Siglo de Torreón describió como "una verdadera razzia”; el rotativo señaló que infringían los

45 "3 Chinese Killed by Villista Band", The Bisbee Daily Review (14 mar. 1919).

46 Chang, Chino, p. 119.

47 Chang, Chino, p. 120; "Juarez Alarmed by Anti-Chinese Pogrom", The Bisbee Daily Review (10 mayo 1919).

48 Chang, Chino, p. 120; "Chinese in Juarez, Mexico, in Fear of Persecution", San Antonio Express (10 mayo 1919).

49 “Ayuntamiento de C. Juárez", Periódico Oficial del Estado de Chibuahua (27 sep. 1924); Chang, Chino, p. 144. 
reglamentos sanitarios y además expendían mercancía adulterada. También publicó que el comité antichino de la ciudad de Chihuahua pretendía que se designara un barrio para los chinos y que se modificara el tratado de amistad con China, habiendo solicitado a la legislatura local que se dirigiera al Congreso de la Unión. ${ }^{50}$ En septiembre de 1925, dirigentes de la Liga Antichina de Torreón, Coahuila, llevaron a cabo una reunión pública en Villa Matamoros, Chihuahua, como parte de su campaña. Al parecer, la liga había enviado cartas a todos los gobernadores del país: entre los que respondieron estaba el de Chihuahua, Jesús Antonio Almeida, quien felicitó a los antichinos, manifestando que "en términos generales estoy de acuerdo con su manera de pensar sobre el particular; considerando también muy necesario buscar los medios más adecuados para evitar la continua invasión del elemento chino". Culpaba a los chinos de haber provocado que comerciantes de Chihuahua hubieran cerrado sus pequeños negocios y solicitaba que le informaran sobre cuáles medidas habían sido exitosas para "restringir la creciente invasión del elemento asiático”. Informaba, además, que en algunas ciudades chihuahuenses se habían tomado "medidas de carácter administrativo, para poner coto al acaparamiento que [los chinos] han hecho de las actividades comerciales". ${ }^{51}$ Unos días después, el 23 de septiembre de 1925, el presidente Plutarco Elías Calles envió una reprimenda a los gobernadores de los estados de Chiapas, Nayarit, Sinaloa, Sonora, Tamaulipas, Yucatán, y del distrito norte del territorio de Baja California, instruyéndoles que respetaran los derechos de los chinos. Temía Calles que de nueva cuenta hubiera una masacre de chinos y quería evitar consecuencias internacionales..$^{52} \mathrm{La}$ reconvención

50 "Perjudicial la inmigración de los asiáticos", El Siglo de Torreón (22 sep. 1925).

51 "Hoy rendirán los ferrocarriles su informe a Calles", El Siglo de Torreón (30 ene. 1925).

${ }^{52}$ Chang, Chino, pp. 150-151. 
no fue necesaria en el estado de Chihuahua: sus antichinos no eran motivo de preocupación para el presidente del país.

En abril de 1926, Hipólito C. Méndez, dirigente del Comité Pro-Raza de la ciudad de Torreón, del vecino estado de Coahuila, declaró que, como resultado de la convención antichina efectuada en Nogales, Sonora, el Comité Antichino de Torreón estaba tratando que la campaña "nacionalista" llegara a otros estados y a las ciudades fronterizas del norte, pues querían evitar que chinos expulsados de Estados Unidos ingresaran a territorio nacional. Pretendía formar un comité antichino en la ciudad de Chihuahua, que se extendiera a Jiménez y a otras localidades con importante presencia china. ${ }^{53}$ En junio del mismo año, en Santa Bárbara se distribuyeron unas hojas que advertían sobre la "invasión" de comerciantes chinos y sobre el dominio que pudieran alcanzar en el ramo de comestibles. Se les acusaba de adulterar la mercancía y de ser antihigiénicos por vivir en sus propios negocios. "Sin distinción de credos", se convocaba a "todos los gremios incorporados y consumidores en general" a participar en un boicot a sus establecimientos. En el mes de julio, en un volante se ponía como ejemplo a Tuxtla Gutiérrez, Chiapas, donde supuestamente había una alarmante cantidad de ciegos debido al tracoma que contagiaban los chinos. Además, se vendió en diez centavos un escrito en verso, titulado El destierro de los chinos, en el cual se señalaba la necesidad de expulsarlos (junto con los árabes), insultando, además, a las mexicanas con las que cohabitaban. ${ }^{54}$ Era una selección de un escrito con el mismo título publicado alrededor de $1910 .{ }^{55}$ La legación China informó a la Secretaría de Gobernación acerca de la difusión de escritos "de carácter perjudicial y deprimente", solicitando la

53 "Los frutos de la campaña de los antichinos”, El Siglo de Torreón (5 abr. 1926).

${ }^{54}$ AGN, DGG, 2.360(6)8027, c. 3, exp. 6, fols. 1-5.

55 Romero, "El destierro de los chinos", pp. 120-122; Avitia, El país de las hojas sueltas, t. III, p. 44. 
intervención del gobierno federal ante las autoridades locales. Haciendo alusión a la reprimenda del 23 de septiembre de 1925, recordaban que el presidente de la República, Plutarco Elías Calles, había manifestado que "con energía desaprueba los movimientos antichinos". El presidente municipal de Hidalgo del Parral, Enrique A. Domínguez, respondió a la instancia federal que no había ni nunca hubo agitación antichina: sólo se habían estado vendiendo unas "mañanitas", lo cual no tenía importancia. Por su parte, el presidente municipal de Santa Bárbara, G. J. Chávez, informó que en los meses de marzo y abril de ese mismo año de 1926, ciudadanos chinos estuvieron acudiendo a las oficinas del ayuntamiento a quejarse de insultos difundidos en unas hojas. Chávez adjudicó la distribución de la propaganda antichina a un solo individuo, "cuyo nombre no recuerdo, pero fue imposible localizarlo" ${ }^{56}$ Ambos funcionarios trataron de minimizar la sinofobia.

El 15 de abril de 1927, el diputado Nicolás Pérez encabezó a un grupo de seguidores del general Marcelo Caraveo quienes, apoyados por la guarnición militar, depusieron al gobernador Jesús Antonio Almeida. ${ }^{57}$ Su caída probablemente se debió a que, gracias a sus nexos con élites porfiristas, podía lograr la cooperación de éstas con las emanadas de la Revolución, lo cual era amenazante para los afanes centralizadores del gobierno federal: no era deseable un gobernador independiente como Almeida. ${ }^{58}$ Manuel Mascareñas quedó como interino. ${ }^{59}$ Debido a que no cumplía con el requisito de ser nativo del estado de Chihuahua, renunció el 8 de mayo de ese mismo año ${ }^{60}$ y lo sustituyó Fernando Orozco, quien había participado en la deposición de

\footnotetext{
56 AGN, DGG, 2.360(6)8027, c. 3, exp. 6, fols. 1-2 y 10-12.

57 Авогтеs, "De Almeida a Quevedo", p. 435.

58 Wasserman, Persistent Oligarchs, p. 40.

59 Авогтеs, "De Almeida a Quevedo", p. 435.

60 Almada, Diccionario de historia, p. 325.
} 
Almeida. ${ }^{61}$ Fue durante su administración, en junio de 1927, cuando la Cámara de Diputados del estado de Chihuahua envió al presidente Elías Calles una iniciativa para prohibir los matrimonios de mexicanas con chinos, expulsar a los que no se encontraran legalmente en el país, y establecer barrios exclusivos para chinos. La iniciativa, similar a la enviada por otros estados, fue rechazada por contravenir la Constitución y, en lo relativo a la expulsión de los inmigrantes no autorizados, por ya existir leyes al respecto. ${ }^{62}$

En septiembre de 1927, en Hidalgo del Parral y sin el conocimiento del delegado de inmigración (dependiente de la Secretaría de Gobernación), un hombre llamado Woo Chay fue detenido por el agente federal Jesús Gutiérrez y encarcelado por no contar con la debida documentación dada su calidad de extranjero. Un comité antichino había señalado la posible entrada ilegal de chinos a la delegación de la Oficina Confidencial de la misma Secretaría de Gobernación, la cual ordenó a Gutiérrez que remitiera a la autoridad municipal a los chinos de Hidalgo del Parral y de San Francisco del Oro. El detenido hizo gestiones en Ciudad Juárez, donde antes residía, para obtener la documentación requerida, dejándosele en libertad. En la ciudad de Chihuahua, Francisco Woo se enfrentó a una situación semejante a la que sorteó Woo Chay. ${ }^{63}$

Gutiérrez también detuvo a Tam $\mathrm{Bu}$, residente de Hidalgo del Parral. La colonia china de esta localidad envió una misiva a la legación, en la cual se informaba que un agente federal había encarcelado chinos con el pretexto de que no contaban con la debida documentación. La legación lo hizo del conocimiento de la cancillería, la cual a su vez lo comunicó a la Secretaría de Gobernación. Por su parte, el gobernador Fernando Orozco

61 Almada, Diccionario de historia, p. 381.

${ }^{62}$ KIM, "Immigrants, Workers, Pioneers", pp. 146-147.

${ }^{63}$ AGN, $D G G, 2.367(6) 1$, c. 1, exp. 26, documentos sin foliación. 
informó de los hechos a esta última por medio de oficio fechado el 27 de septiembre y recibido el 15 de octubre. No obstante, el 7 de octubre el delegado de migración radicado en Ciudad Juárez envió un telegrama a la Secretaría de Gobernación aclarando que no se había dado ninguna orden para la revisión de los pasaportes de los chinos de Parral, sino que la Liga Nacionalista Antichina había estado haciendo esas inspecciones. La Oficina Confidencial de la Secretaría de Gobernación envió un memorándum el 19 de octubre al jefe de Relaciones, Gobernación y Justicia de la mencionada secretaría, informándole que, como respuesta a la queja del Comité Antichino sobre la posible entrada ilegal de muchos chinos, se había ordenado al agente Jesús Gutiérrez que remitiera a la autoridad municipal a los chinos de Hidalgo del Parral y de San Francisco del Oro que no pudieran comprobar su legal estancia en el país, habiéndose detenido a un individuo de nombre Tam Bu. En documento fechado el 25 de octubre, Relaciones Exteriores solicitó a la Secretaría de Gobernación información sobre la legalidad de los procedimientos de inspección de la liga antichina, indicándosele que, en caso de no ajustarse a la ley, debería dar las órdenes necesarias para que la liga suspendiera ese tipo de acciones. Sin negar que Tam $\mathrm{Bu}$ hubiera entrado al país de forma ilegal, la Secretaría de Gobernación, en escrito fechado el 29 de noviembre de 1927, señaló al jefe del Departamento de Relaciones, Gobernación y Justicia que, como deferencia a la legación china, debía ponerse en libertad a Tam $\mathrm{Bu}$, pues muchos extranjeros estaban en la misma situación y no se había acordado una investigación general al respecto, de manera que la expulsión de una persona no sería equitativa. La Secretaría de Gobernación, por medio de un telegrama fechado el 15 de diciembre, indicó al gobernador del estado que liberara a Tam Bu. El gobernador Orozco respondió por la misma vía al día siguiente, afirmando que inmediatamente se había ordenado al presidente municipal de Hidalgo del Parral la liberación del mencionado extranjero. Comunicó, además, que según este 
alcalde, la Secretaría de Gobernación había cometido un error, pues ningún chino estaba encarcelado en la localidad. ${ }^{4}$ Por segunda ocasión el presidente de Hidalgo del Parral, Enrique A. Domínguez, negaba la existencia de acciones antichinas.

En 1928, el estado de Chihuahua comenzaba una época de depresión económica y sequía. ${ }^{65}$ A pesar de la situación, la colonia china de Jiménez, con invitados mexicanos, celebró el 10 de octubre de 1928 el aniversario de la República China, izándose las banderas china y mexicana. Hubo banquete, vinos y orquesta. ${ }^{66} \mathrm{Al}$ día siguiente, la colonia de la ciudad de Chihuahua, "por conducto de la Logia Progreso número 15”, hizo lo propio. El cónsul chino en la ciudad "ofreció solemne recepción a sus connacionales”. Se efectuó también la Quinta Gran Convención de Logias Chinas. Llegaron a la ciudad delegados de Monterrey, Tuxpan, Zacamixtle, Pánuco, ciudad de México, San Luis Potosí, Tampico, Torreón, Hermosillo, Puerto México y Guadalajara. De Tapachula llegó Guillermo F. Gay, presidente del Comité Central Pro-Logias Chinas en la República Mexicana. Arribaron también los delegados de la ciudad de Chihuahua, Hidalgo del Parral, Ciudad Juárez, Madera y Casas Grandes. Asimismo, estuvo presente el delegado de San Francisco, California. No sólo asistieron chinos, sino también otros masones chihuahuenses. ${ }^{67}$ Lázaro Villarreal, empresario mueblero, ${ }^{68}$ a nombre de la Logia Cosmos dio la bienvenida a los visitantes. El delegado en Chihuahua Juan Ham King, nombrado por el ministro

\footnotetext{
${ }^{64}$ AGN, DGG, 2.367(6)1, c. 1, exp. 26, documentos sin foliación.

${ }^{65}$ Авогтеs, "De Almeida a Quevedo", pp. 439-440.

66 "Los asiáticos celebraron el aniversario de la república”, en El Siglo de Torreón (14 oct. 1928).

67 "Convención de las logias chinas se efectuó en Chihuahua", El Siglo de Torreón (13 oct. 1928).

68 “Recluso 95/563, alcalde de Juárez”, en Proceso (17 abr. 1995), http://www. proceso.com.mx/168786/recluso-95563-alcalde-de-juarez-yo-asumo-loscompromisos-a-muerte-el-grito-en-la-calle-debe-ser-federalismo. Consultado el 10 febrero de 2018.
} 
plenipotenciario de la República China, se encargó de traducir los discursos al castellano. Hubo banquete, brindis, y la banda del 70 Regimiento de la Guarnición de la Plaza tocó piezas musicales. ${ }^{69}$ También en Hidalgo del Parral hubo celebración; el 14 de octubre, además de chinos de esa ciudad, asistieron de Jiménez, Santa Bárbara, San Francisco del Oro y Villa Escobedo. Estuvieron presentes el presidente municipal, el agente del ministerio público, funcionarios de juzgados, el diputado federal por el distrito, empresarios, empleados bancarios y el presidente del sindicato de obreros. Hubo música, teatro, y poesía, siendo los intérpretes artistas locales y alumnos de escuelas parralenses. ${ }^{70}$ Estas celebraciones muestran que los chinos guardaban buenas relaciones con amplios sectores de la sociedad chihuahuense.

El general Marcelo Caraveo tomó posesión como gobernador para el periodo 1928-1932, pero en marzo de 1929 se unió al levantamiento escobarista. ${ }^{71}$ De las confianzas del gobierno federal ${ }^{72}$, Luis L. León tomó protesta como gobernador en abril de 1929 y recibió la tesorería del estado prácticamente vacía. Despidió empleados, cerró dependencias y reconoció que no podría realizar obras públicas. Se presentaron marchas de desempleados en Ciudad Juárez y escasez de alimentos como resultado de las pésimas cosechas. El gobierno del estado trató de paliar la situación por medio de un crédito de 20000 pesos para la compra de granos básicos. Además, Portes Gil, presidente de la República, donó 90 toneladas de maíz. La crisis de 1929 acentuó la deplorable situación económica del estado. La baja del precio de la plata también golpeó la economía estatal,

69 "Convención de las Logias chinas se efectuó en Chihuahua", El Siglo de Torreón (13 oct. 1928).

70 "Una comida campestre a los vencedores en maniobras", El Siglo de Torreón (15 oct. 1928).

71 Aвoites, “De Almeida a Quevedo", pp. 432, 437-438.

72 Wasserman, Persistent Oligarchs, p. 41. 
así como las restricciones a la importación ganadera impuestas por el gobierno de Estados Unidos. ${ }^{73} \mathrm{El}$ gobernador León fue llamado a la campaña presidencial del candidato Pascual Ortiz Rubio, por lo cual se ausentó del 3 de julio al 9 de noviembre de 1929. De nuevo se separó del cargo del 6 de diciembre de 1929 al 5 de febrero de 1930, cuando renunció para asumir la titularidad de la Secretaría de Industria, Comercio y Trabajo como parte del gabinete del presidente Ortiz Rubio. ${ }^{74}$ La ausencia de León fue suplida por Francisco R. Almada. ${ }^{75}$ El 24 de noviembre de 1929, Reynaldo Talavera fue electo presidente municipal de Chihuahua. ${ }^{76}$ El comerciante José Mac Tanyes, presidente del Kuo Ming Tang, Partido Nacionalista Chino en Chihuahua, y el secretario de negocios en español Fong Yuen, felicitaron al nuevo alcalde. Aunque la misiva iba dirigida a “Ángel Talavera”, el recién electo presidente municipal agradeció la felicitación, afirmando que llegaba al puesto "animado de los mejores deseos de prestar las garantías debidas a todas las negociaciones en general”;77 tal declaración lleva a suponer que no favorecía a los antichinos.

En abril de 1930, comerciantes chinos se dirigieron a la autoridad municipal por otros motivos. Samuel Cuan Min y R. Cuan Min solicitaron al alcalde que se les permitiera abrir sus tiendas los domingos, ya que muchos otros pequeños negocios así lo hacían. ${ }^{78}$ Pidieron lo mismo en otra misiva con idéntica redacción los comerciantes chinos del nuevo mercado Enrique Woo, Santiago Chong, Francisco Young, Carlos Foy, Jesús Woo, Lorenzo Hernández, junto con los japoneses José Hayashi, Narciso Abe, Enrique Suzuki, J. Yshida, y los mexicanos Antonio Sáenz, Antonio Lara, Albino Alvarado, Margarita

73 Aвortes, "De Almeida a Quevedo", pp. 439-441.

74 Almada, Diccionario de historia, p. 308.

75 Almada, Diccionario de historia, p. 29.

76 "Resultado", Periódico Oficial del Estado de Chibuahua (30 nov. 1929).

77 AHMCH, $R, S$, c. 80, exp. 4, documento sin foliación.

78 AHMCH, $R, S$, c. 80, exp. 4, documento sin foliación. 
Vázquez, Jesús Lozano Ruiz, G. A. viuda de Aguirre, Zeferino Garrido, Marcelo Sáenz, Enrique Peña y María Juana de León, entre otros. ${ }^{79}$ Aunque la petición fue denegada por existir un acuerdo "entre la mayor parte de los comerciantes" para que todos descansaran el domingo, ${ }^{80}$ fue ostensible que, independientemente de su nacionalidad, los solicitantes habían unido sus voces en la causa común.

En marzo de 1930, más de cien personas formaron en la ciudad de Chihuahua un comité antichino para "emprender una batida contra los matrimonios con chinos", por considerar que esto constituía "un paso hacia la degeneración de la raza". Aclararon que no deseaban "extorsionar a los chinos" ni pretendían "crear dificultades al gobierno". ${ }^{81}$ Su objetivo era sólo "la vigilancia moral de nuestras mujeres", es decir, evitar que cohabitaran con chinos. De acuerdo con el Quinto Censo de Población 1930, en la ciudad de Chihuahua residían 185 nacidos en China; 33 de ellos vivían en pareja con mujer mexicana. ${ }^{82}$ Esta Alianza Nacionalista Chihuahuense, coaligada con la Unión Nacionalista Mexicana Pro Raza y Salud Pública, ${ }^{83}$ tenía como lema "Raza y Cultura": ${ }^{4}$ no sólo pretendía proteger la presunta integridad genética de los chihuahuenses sino también salvaguardar la pureza de su cultura.

79 AHMCH, $R, S$, c. 80, exp. 4, folio 1649 y documento sin foliación. La nacionalidad de los locatarios cuya firma es legible se investigó en el Quinto Censo de Población 1930 en Ancestry.mx, https://search.ancestry.mx/search/ db.aspx?dbid=1771. Consultado el 2 de febrero de 2017.

80 AHMCH, $R, S$, c. 80, exp. 4, documentos 1608, 1648/11-930 y 1649.

81 “Tratan de evitar los matrimonios con asiáticos”, El Heraldo de Chibuabua (14 mar. 1930).

82 Conteo propio a partir de los datos del Quinto Censo de Población 1930 en Ancestry.mx, https://search.ancestry.mx/search/db.aspx?dbid=1771. Consultado el 22 de marzo de 2019.

83 "Fines que persigue la Alianza Nacionalista”, El Heraldo de Chibuabua (26 abr. 1930).

84 AGN, DGG $2.360(6) 8027$, c. 3, exp. 6, documento sin foliación. 
La formación de la alianza despertó pronta preocupación en los chinos. La Unión Fraternal de la Colonia China dirigió una carta a la Cámara Nacional de Comercio de Chihuahua en la cual preguntaba si debían temer acciones del comité antichino. La respuesta de la Cámara, fechada el 29 de marzo, era de total confianza en que las autoridades protegerían a los chinos, pues habían conocido casos similares y, además, el “C. Presidente de la República [Plutarco Elías Calles] giró una circular a fines de junio de 1927 dirigida a todos los C. C. Gobernadores de los estados [...] recomendándoles [...] impartir sin reserva la protección y garantías a base de igualdad" a los chinos que vivieran en el territorio nacional. ${ }^{85}$ Como era de esperarse, el comunicado de la Cámara no fue muy tranquilizador: el 4 de abril de 1930 la Unión Fraternal de la Colonia China envió una carta al gobernador provisional Francisco R. Almada, "expresándole los temores que abrigaban algunos de sus miembros de ser víctimas de actividades hostiles”. El secretario general de Gobierno Walterio M. Sein escuetamente respondió afirmando que de acuerdo con las leyes del estado de Chihuahua, "todos los súbditos Chinos [sic] gozarán, como hasta la fecha, de todas las garantías individuales que las mismas les impartan”. La Unión Fraternal de la Colonia China se declaró complacida con las atenciones que había recibido del gobernador. ${ }^{86}$

Sin embargo, la respuesta de la Alianza Nacionalista Chihuahuense no se hizo esperar: en el periódico El Heraldo de Chibuabua, el 26 de abril de 1930 se publicó una carta abierta de la referida asociación en que calificaron de "injustificada" la alarma de los miembros de la colonia china pues "los componentes de

85 "Pro-colonia china”, El Correo de Chibuabua (1a abr. 1930); "La ley ampara a los comerciantes chinos", El Heraldo de Chibuabua (2 abr. 1930).

86 "Hacen aclaraciones sobre la labor antichina", El Heraldo de Chibuabua (23 abr. 1930). "En pro de la colonia china", El Correo de Chibuabua (24 abr. 1930). 
la agrupación" eran "todas personas laboristas, moderadas y concientes". Además, protestaban "enérgicamente" por las declaraciones de los representantes de la colonia china, quienes habían manifestado que el lema de la Alianza les parecía agresivo. El espíritu de confrontación de la agrupación se hizo evidente cuando expresaron su deseo de "saber concretamente lo que de nuestro grupo teme la Unión Fraternal de la Colonia China de Chihuahua". ${ }^{87}$

Para el periódico El Correo de Chibuabua, el problema era económico: en un editorial del 10 de abril se adjudica la campaña xenofóbica a la competencia comercial que hacían los chinos. ${ }^{88}$ De esta forma, se descalificaba la oposición a los extranjeros por obedecer a intereses pecuniarios. No obstante, en ese mismo mes de abril, la Alianza Nacionalista Chihuahuense informó que había recibido adhesiones en diferentes partes del estado en su combate contra los matrimonios entre chinos y mexicanas. También mencionaron el entusiasmo con que los habitantes de Ávalos (poblado cercano a la ciudad de Chihuahua) apoyaban su lucha quienes, además, estaban formando su propia delegación de la Alianza. ${ }^{89}$

Los sinófobos contaban con su propio medio de información. El día 13 de abril de 1930, en el número 8 del periódico antichino La Idea Libre, como si fueran autoridades migratorias, los sinófobos ofrecieron hacer la "consiguiente rectificación" a los chinos que acudieran a ese medio a comprobar que estaban cumpliendo con la ley de extranjería. ${ }^{90}$ Además, La Idea Libre aclaraba que no debía ofenderse a los "viejos clientes del

\footnotetext{
87 "Fines que persigue la Alianza Nacionalista", El Heraldo de Chibuabua (26 abr. 1930).

88 "Versiones propias y ajenas", El Correo de Chibuabua (10 abr. 1930).

89 “Agrupación contra el matrimonio con asiáticos", El Heraldo de Chibuabua (12 abr. 1930).

90 "A la colonia china", La Idea Libre (13 abr. 1930).
} 
comercio chino en pequeña escala". ${ }^{91}$ Así, los sinófobos trataban de evitar la antipatía de los consumidores chihuahuenses. En el número siguiente, La Idea Libre publicó un artículo signado por Pitacio (probablemente Epitacio Orta) en el cual señalaba lo grave del mestizaje de chinos con mexicanas, "pues es verdaderamente lamentable que a la mujer mexicana se le haya olvidado que desciende de una raza pura, digna de admiración, y no así, de cenegal [sic] detestable por todas las razas civilizadas”. ${ }^{92}$ En páginas interiores se conminaba a que se hiciera labor nacionalista comprando en negocios mexicanos; ${ }^{93}$ además, se puntualizaba que el sudor de los chinos podía infectar sus mercancías. También equiparaba a los chinos con las moscas pues "todo lo que tocan infectan. No compre usted a los chinos". 94

El mes de mayo Luis Fong y Santiago Mar, representantes de los comerciantes chinos de la ciudad de Chihuahua, a instancias del presidente municipal se reunieron con Victoriano Calderón y Agustín Elizalde, respectivamente director y administrador del periódico La Idea Libre. Los líderes chinos solicitaron al ayuntamiento que cesaran los ataques de la mencionada publicación. Los directivos del periódico quedaron obligados a abstenerse de acusaciones no comprobadas. Debían mantener su campaña antichina "siempre dentro de la ley" ${ }^{95}$ Así, la posición de la autoridad local fue proteger a los chinos de la calumnia, aunque sin prohibir la campaña xenofóbica. Por su parte, el gobernador Almada se negó a limitar la propaganda antichina de La Idea Libre, según lo había solicitado la Unión Fraternal de la Colonia China de Ciudad Juárez a la Secretaría de Relaciones

\footnotetext{
91 “Nuestra labor antichina en nuestro próximo número", La Idea Libre (13 abr. 1930).

92 Pitacio, “Amenaza un grave peligro a nuestra raza”, La Idea Libre (20 abr. 1930).

93 Sin título, La Idea Libre (20 abr. 1930).

94 Sin título, La Idea Libre (20 abr. 1930).

95 AHMCH, $R, P$, c. 22, exp. 9, documento sin foliación.
} 
Exteriores, pues había libertad de expresión: no podía contravenirse el artículo séptimo de la Constitución, además de que los chinos en Chihuahua "gozaban de todas las garantías constitucionales a que tienen derecho". ${ }^{96}$

En septiembre de 1930, ya con Andrés Ortiz como gobernador, ${ }^{97}$ la Alianza Nacionalista Chihuahuense inició la publicación de un semanario llamado La Raza, el cual tenía como objetivo "señalar la inconveniencia de que muchos de nuestros ramos y hasta mujeres mexicanas vayan a ser propiedad de la raza mongola", ${ }^{98}$ lo cual parece confirmar el trasfondo económico del antichinismo. La Raza convocó a un concurso para responder a la pregunta “¿por qué es inconveniente que la mujer mexicana contraiga matrimonio con individuos de nacionalidad china?", con premios de diez y de cinco pesos. ${ }^{99}$ El director de la publicación era Vito Aguirre, antiguo diputado federal ${ }^{100}$ y miembro de la Junta Patriótica del Ayuntamiento de Chihuahua. ${ }^{101}$

En octubre de 1930, la Liga Nacionalista Anti-China de Ciudad Juárez publicó un manifiesto a la nación en el cual describían a los chinos como "individuos de aspecto repugnante", "portadores de asquerosas enfermedades", caracterizados por su "egoísmo innato, su rapacidad y sus vicios destructores". Luego de acusarlos de excluir a los mexicanos de diversos rubros comerciales y de la agricultura en varios estados del país, encomiaba a la población a no comprar ni vender nada a los chinos, sobre

\footnotetext{
${ }^{96}$ AGN, DGG, 2.360(6)8027, c. 3, exp. 6, fols. 17-18 y 20-21.

97 Авогтеs, "De Almeida a Quevedo", p. 443.

98 "Nuevo periódico", El Correo de Chibuahua (26 sep. 1930).

99 "A través de la República, al revisar prensa diaria del país", El Correo de Chibuabua (30 sep. 1930).

100 DGCP, Legislatura XXVIII, año I, periodo ordinario, 18 de diciembre de 1918, número de diario 101, http://cronica.diputados.gob.mx/ DDebates/28/1er/Ord/19181218.html. Consultado el 2 de marzo de 2019. 101 “Ayuntamiento de Chihuahua”, Periódico Oficial del Estado de Chibuabua (30 ene. 1926).
} 
todo a crédito. También pedía a los mexicanos que solicitaran a las autoridades la aplicación rigurosa de las leyes y reglamentos a los chinos para que pagaran los debidos impuestos y para "evitar la propagación de las enfermedades que padecen”. Además, debía solicitarse a las autoridades la vigilancia de los chinos para evitar que sacaran del país "cantidades de oro nacional acuñado, causa determinante" de "la terrible depreciación de la Plata". Asimismo, debía evitarse el ingreso ilegal de chinos e impedir su naturalización. No conformes con lo anterior, había de legislarse para prohibir "las monstruosas uniones" entre chinos y mexicanas, en las cuales "el amor no interviene para nada"; se estaba incubando un "México híbrido”, el cual amenazaba con destruir "las excelencias de nuestra Raza, y por ende el orgullo de nuestra nacionalidad”. ${ }^{102}$ La Unión Fraternal de la Colonia China de Ciudad Juárez envió una misiva con un ejemplar del "Manifiesto a la Nación” a la Secretaría de Gobernación, misma que fue turnada a Relaciones Exteriores y al gobernador de Chihuahua Andrés Ortiz. A este último las autoridades federales le solicitaron que impartiera las garantías de ley a los chinos, pues en la carta ellos denunciaban que con toda impunidad se había desatado una campaña de "propaganda sediciosa contra los intereses de ciudadanos chinos”, la cual había llegado al escarnio y la humillación. ${ }^{103}$

En artículo editorial, el 23 de octubre de 1930, El Correo de Chibuabua calificó de inmoral la campaña antichina, pues la consideraba con "fines lucrativos muy personales", aunque también señalaba que "nadie ignora que la raza mongola no es ni con mucho la más afín a la nuestra” además "de ser una amenaza para los hogares mexicanos", pues muchas mujeres, "por su inconciencia”, podían verse atraídas por la "laboriosidad y espíritu de ahorro” de los chinos, lo cual les permitía hacerse de capitales

102 AGN, DGG $2.360(6) 8027$, c. 3, exp. 6, documento sin foliación.

103 AGN, DGG, 2.360(6)8027, c. 3, exp. 6, fols. 25 y 26. 
que los mexicanos no lograban debido a su espíritu "dispendioso y despilfarrador". ${ }^{104}$ Aunque El Correo censuraba la hipocresía de los antichinos, consideraba la miscegenación de las razas mongola y mexicana como inconveniente. ${ }^{105} \mathrm{La}$ presencia de esos extranjeros era aceptada, pero en el plano económico.

El Correo se declaró solidario con los chinos en referencia a un remitido del Casino Chino publicado en el mismo número, en el cual se desmentía que en el referido centro de reunión se fumara opio y se permitieran juegos prohibidos, como lo había publicado el semanario La Raza. Señalaban como testigos a los policías a cargo de la vigilancia del local. Sospechaban que había difundido la falsa noticia un individuo, cuyo nombre omitieron, que infructuosamente había tratado de extorsionarlos. ${ }^{106}$

La publicación de La Raza, sin embargo, continuó. En el número del 26 de octubre de 1930, en un suelto, se culpaba a los chinos de vender las legumbres más baratas a sus connacionales y de que en tiempos de escasez sólo a ellos se las expendían. Se volvió a acusar al Casino Chino de permitir actividades ilícitas. Vito Aguirre, director de La Raza, conminó a que se diera el nombre del presunto extorsionador. Este número de la referida publicación llevó a los directivos de la Unión Fraternal de la Colonia China y del Casino Chino a enviar comunicados a El Correo a finales de octubre de 1930, en los que desmentían lo publicado en La Raza. El presidente y el secretario del Casino Chino enviaron una tercera carta abierta, en la cual daban respuesta a la conminación de Aguirre, negándole toda autoridad para hacer solicitudes de esa índole y manifestando su derecho a

104 "Deben las autoridades evitar la labor inmoral en caso de q' exista", El Correo de Chibuahua (23 oct. 1930).

105 Para una detallada discusión al respecto, véase Treviño, "Racismo y nación”.

106 "El Casino Chino hace aclaraciones", El Correo de Chibuabua (23 oct. 1930). 
guardar la información de acuerdo con sus propios intereses. ${ }^{107}$ Dado que el hostigamiento a los chinos se presentaba en varias partes del país, la Secretaría de Gobernación envió una circular a los gobernadores de los estados para que evitaran "molestias injustas a los chinos" inmigrados de forma ilegal. Una nota de la redacción de El Correo consideraba necesaria tal disposición pues los antichinos sólo buscaban "la manera de explotar a sus mismos atacados, acción que constituye una inmoralidad". ${ }^{108}$ Suscribía así El Correo la acusación de la Unión Fraternal de la Colonia China respecto de que se les intentaba extorsionar.

La Secretaría de Gobernación recibió un escrito con fecha del 7 de noviembre de 1930 en el cual se notificaba la constitución de la Liga Nacionalista Anti-China de Ciudad Juárez, misma que había publicado el "Manifiesto a la Nación” el 23 de octubre. La razón para crear la agrupación, se argüía, era "que la generalidad de los negocios en esta ciudad está en poder de extranjeros, y muy especialmente entre los chinos, que controlan los establecimientos de abarrotes y regular número de carnicerías". Los mexicanos deportados diariamente por Estados Unidos a esa frontera no encontraban trabajo "en ninguna parte, ni en las tiendas", debido a que "los propietarios chinos emplean chinos, en número de tres a quince $[. .$.$] y si no se les pone un dique,$ controlarán todo con grave perjuicio de la comunidad nacional". Se mencionaba que, "por medio de la persuasión y dentro del orden”, habían estado emprendiendo una campaña para que se comprara en establecimientos mexicanos y se consumieran artículos nacionales. Los distintos niveles de gobierno, señalaban, podían "cooperar tan solo exigiendo a los extranjeros que cumplan con las Leyes y Reglamentos que nos rigen”. La Secretaría de Gobernación informó de lo anterior al gobernador

107 “Aclaraciones de la Unión Fraternal de la Colonia”, El Correo de Chibuabua (29 oct. 1930).

108 "No serán molestados los chinos que hayan cumplido con la ley", El Correo de Chibuabua (6 nov. 1930). 
del estado; a la Liga Nacionalista Anti-China de Ciudad Juárez le respondió que "ya se han dictado, y se encuentran en vigor, disposiciones relativas a la cuestión de Migración y respecto de los otros puntos, estos se hacen del conocimiento del C. Gobernador de ese Estado para los fines consiguientes". 109

Por su parte, Chon Sam Lee y Samuel Chávez, representantes de la colonia china juarense, viajaron a la ciudad de Chihuahua y presentaron su queja por escrito ante el gobierno del estado: los comerciantes chinos de Ciudad Juárez eran víctimas de "intemperancias e injurias" de parte de los sinófobos. El Correo de Chibuahua esperaba que, en caso de ser veraz la denuncia, el Ejecutivo del estado hiciera válidas a los chinos las garantías a que tenían derecho, pues los mexicanos "estamos obligados a dar muestras de cultura siquiera sea por la vecindad con los Estados Unidos”. Además, El Correo publicó que las autoridades habían actuado con tibieza, pues no habían hecho comprender a los líderes de la campaña antichina su obligación de respetar los derechos de los chinos. De esta forma, a su postura de descalificación de la campaña antichina por adjudicarla a intereses económicos, El Correo añadió una acusación a las autoridades por permitir excesos. No conforme con lo anterior, dio a conocer que en Hidalgo del Parral aparecieron destrozadas bancas de la Plaza Hidalgo, las cuales habían sido donadas por la colonia china local. Manifestó su deseo de que las autoridades parralenses abrieran una averiguación al respecto y se castigara a los culpables. ${ }^{110}$ Por su parte, el gobernador Ortiz respondió a los chinos radicados en Ciudad Juárez garantizándoles la protección de la ley. La colonia china juarense también se dirigió al presidente municipal Jesús Quevedo para solicitar protección. ${ }^{111}$

109 AGN, DGG, 2.360(6)8027, c. 3, exp. 6, fols. 29 y 31-32.

110 "Labor improcedente en Ciudad Juárez e H. del Parral”, El Correo de Chibuahua (12 nov. 1930).

111 “El gobernador contesta a la U.F. Asociación china”, El Correo de Chibuabua (17 nov. 1930). 
El 13 de noviembre de 1930, en la colonia industrial de la capital del estado, se formó el Comité Antichino número 1, adherido a la Alianza Nacionalista Chihuahuense. Epitacio Orta fungía como presidente y Alfredo Morales como secretario. Manifestaban que "es ya insostenible la ola de odio que se hace sentir en nuestros connacionales hacia los asiáticos" debido a los perjuicios que causaban. Solicitaban la ayuda de sindicatos, instituciones gubernamentales, particulares y especialmente de "la prensa que aún se siente mexicana". ${ }^{112}$ El 19 de noviembre, El Correo de Chibuahua dio a conocer la noticia, reconociéndole al joven Orta "talento y facultades." 113 Sin embargo, le recomendaron que leyera con detenimiento los artículos publicados por El Correo a partir de esa edición, pues consideraban el asunto muy delicado. Los artículos aludidos eran de Zeferino M. Mares, quien recurrentemente hacía énfasis en que el mexicano antepusiera la autocrítica a la xenofobia:

[...] allí están los chinos, que nos están dando lecciones de lo que es ser trabajador y ahorrativo, y tal como somos de buenos para nada, nos asustamos de los defectos que, como humanos que son, tienen, pero no les imitamos sus virtudes ni damos una mirada a nuestros propios defectos para luego meternos a moralizadores. Queremos ser puritanos cuando llevamos tras de sí [sic] una carga de defectos que nos ruborizarían si tuviéramos la entereza de observarnos desligados de prejuicios y de egoísmos. ${ }^{114}$

En otro artículo, afirmó Mares:

112 AHMCH, $R, S$, c. 80, exp. 4, documento sin foliación.

113 "El comité antichino número 1 nos envía una atenta circular”, El Correo de Chibuabua (19 nov. 1930).

114 Mares, “¿Por qué estamos tan pobres?”, El Correo de Chibuabua (30 oct. 1930). 
Y los chinos, pongamos por caso, no adolecen de estos defectos que tenemos nosotros, que saben ser unidos, laboriosos y si ganan cinco pesos gastan dos, y no diez o quince como la inmensa mayoría de nosotros, la consecuencia es lógica, tienen que prosperar y nosotros ser eternamente unos fracasados. ${ }^{115}$

En clara alusión a la campaña contra los matrimonios de mexicanas con chinos, Mares escribió:

Nos admiramos y hasta maldecimos a nuestras mujeres porque se casan con individuos que vendrán a degenerar a nuestra raza y hasta criticamos a los de color, creyendo que llevamos sangre azul en nuestras venas pero no analizamos la causa de estos defectos sociales que arrastran a nuestras abnegadas mujeres mexicanas a cruzarse con otras razas. ${ }^{116}$

La labor “extranjerista” recomendada por Zeferino M. Mares era que se prefiriera comprar en los comercios mexicanos a los extranjeros, siempre y cuando los connacionales hubieran logrado hacerse de su negocio honradamente, como producto de su trabajo. ${ }^{117}$ Mares reconocía virtudes en los chinos y aun los ponía de ejemplo, criticando al mismo tiempo a los mexicanos. Sin embargo, en igualdad de condiciones, proponía la preferencia a sus compatriotas. Aunque los párrafos citados previamente tienen un sentido aparentemente xenofílico, la labor “extranjerista” prescrita por Mares no deja de ser xenofóbica. Esta mezcla ha sido señalada como característica de los mexicanos frente al extranjero. ${ }^{118}$

115 Mares, "La fobia contra los extranjeros”, El Correo de Chibuabua (19 nov. 1930).

116 Mares, "Cómo se debe hacer labor extranjerista”, El Correo de Chibuabua (20 nov. 1930).

117 Mares, "Cómo se debe hacer labor extranjerista”, El Correo de Chibuahua (20 nov. 1930).

118 Buchenau, “Small Numbers, Great Impact”, p. 24. 
A nivel nacional, el año de 1931 fue el de mayor repatriación de mexicanos residentes en Estados Unidos. Fue también uno de intensas campañas a favor de la raza, la economía y la cultura mexicanas. ${ }^{119}$ En Chihuahua, en febrero de ese año, los antichinos redactaron un documento dirigido al Congreso del estado solicitando su apoyo. El Correo de Chibuahua reprobó la petición, recomendando a los "antiextranjeros" que "procuremos todos los mexicanos primero enseñarnos a ser trabajadores, ahorrativos, previsores y menos holgazanes y viciosos para tener derecho a fiscalizar a los extranjeros que vienen a ponernos el ejemplo de trabajadores y unidos". ${ }^{120}$ No obstante, unas cuantas semanas después, El Correo publicó una enérgica protesta contra un plan del Congreso de California que pretendía eliminar las escuelas de niños mexicanos y "refundir" al personal escolar en instituciones de chinos. ${ }^{121}$ Así, la xenofobia de El Correo se volvió a manifestar.

Al mes siguiente, el líder antichino sonorense José Ángel Espinoza envió una misiva al ayuntamiento de la ciudad de Chihuahua, presidido por Reynaldo Talavera, solicitando que cada miembro adquiriera un ejemplar de su libro ("magna obra" en palabras de Espinoza) El problema chino en México. Con recursos propios, 12 regidores compraron el libro. ${ }^{122}$

El 8 de abril de 1931, la Secretaría de Gobernación recibió una carta de una Liga Nacionalista en Ciudad Juárez, en la cual se informaba de la creación de dicha agrupación que tenía como propósito "cooperar con el gobierno general de la república, a la resolución del problema nacionalista que en estos momentos conmueve al país". Su lema era "Por la Patria y por la Raza". Esta liga muy pronto se vio envuelta en conflictos internos.

119 González Navarro, Los extranjeros en México, vol. III, p. 300.

120 “Continúa la campaña contra los asiáticos”, El Correo de Chibuabua (4 feb. 1931).

121 "Enérgica protesta”, El Correo de Chibuahua (23 mar. 1931).

122 AHMCH, $R, P$, c. 25, exp. 4, fols. 152, 170 y documentos sin foliación. 
Unas semanas después expulsó a su presidente y al director de su medio de difusión, El Nacionalista. ${ }^{123}$

En el mes de mayo de 1931, Juan Y. Fong, secretario de la Unión Fraternal de la Colonia China, envió al Congreso del estado su postura frente a la petición de leyes antichinas. Adjudicó ésta a que algunos directores de los comités sinófobicos eran comerciantes y buscaban protegerse al margen de la ley, ya que los negocios de los chinos "constituían competidores de fuerza, por virtud de los bajos precios a que en dichos establecimientos se expenden los alimentos" pues el comerciante chino se limitaba a obtener bajas utilidades. Asimismo, desmentía las acusaciones de "temibles enfermedades y falta absoluta de aseo" que los sinófobos lanzaron a los chinos para buscar apoyo en su campaña de boicot. Fong esgrimió las garantías otorgadas por la Constitución para pedir que se desechara la petición de los antichinos "por improcedente”, pues éstos pretendían que el Congreso del estado declarara según su conveniencia. Además, les recordó a los diputados locales, tal ley no podría entrar en vigor, pues estaría en contra de la Carta Magna. ${ }^{124}$ El Correo de Chibuahua puntualizó el derecho de los chinos a defenderse y señaló que había gente interesada en eliminarlos del comercio y la agricultura, reiterando que el verdadero origen de la campaña antichina eran los intereses económicos; ${ }^{125}$ aún más, en una nota del 19 del mismo mes y año, se burló de los sinófobos por darle al Casino Chino un nombre equivocado. ${ }^{126}$

La Secretaría de Gobernación recibió el día 18 de septiembre de 1931 una queja de la Unión Fraternal de la Colonia China de

\footnotetext{
${ }_{123}$ AGN, DGG, 2.360(6)8027, c. 3, exp. 6, fols. 50 y 55.

124 "Memorial de la H. Colonia China a los Señores Diputados", El Correo de Chibuabua (4 mayo 1931).

125 "El chino no busca más que defenderse de sus detractores", El Correo de Chibuabua (16 mayo 1931).

126 "Son lingüistas los que se autotitulan líderes de la raza", El Correo de Chibuabua (19 mayo 1931).
} 
Nuevo Casas Grandes por la difusión de propaganda sinofóbica en la zona. ${ }^{127}$ Esta Unión adjuntó un ejemplar del periódico El Regional, donde se informaba que se había formado un comité antichino con más de un centenar de personas. El ejemplar incluía un artículo propagandístico de la Unión Nacionalista Mexicana Pro-Raza y Salud Pública firmado por J. R. Salazar, donde aparecía la frase "asqueroso mongol", así como un editorial que hacía burla del castellano hablado por los chinos. ${ }^{128}$ Por otra parte, el 19 de octubre el "Club Juvenil de Amigos" de la localidad de Porvenir dirigió una misiva al secretario de Gobernación solicitando la expulsión de varios chinos por ser "un peligro para la salubridad pública". ${ }^{129}$

En Casas Grandes, el 22 de septiembre de 1931 Juan Fong fue asaltado y golpeado. Aun cuando se tenía identificados a los malhechores, las autoridades municipales no tomaron cartas en el asunto: el secretario del Ayuntamiento era directivo del Comité Antichino de Casas Grandes. Esta agrupación había difundido propaganda sinofóbica y amenazado con expulsar a los chinos de la localidad si no cumplían con la nueva Ley Federal del Trabajo. De acuerdo con la Unión Fraternal de la Colonia China, los sinófobos falsamente afirmaban que los chinos de Casas Grandes y Nuevo Casas Grandes preferían marcharse antes que acatar la nueva ley, por lo cual estaban rematando su mercancía. Se trataba de una maniobra para provocar incidentes contra los chinos. ${ }^{130}$

En vista de la escandalosa corrupción de su administración, el Partido Nacional Revolucionario (PNR) depuso a Andrés

\footnotetext{
127 AGN, DGG, 2.360(6)8027, c. 3, exp. 6, fol. 56.

128 AGN, DGG, 2.360(6)8027, c. 3, exp. 6, fol. 57; "Se instaló un comité antichino en este lugar"; J.R. Salazar, "Pirandeleando"; "A nosotros que te impota [sic]", El Regional (13 sep. 1931).

${ }_{129}$ AGN, DGG, 2.360(6)8027, c. 3, exp. 6, fol. 66.

130 "Unión Fraternal, Asociación China", El Correo de Chibuabua (3 oct. 1931).
} 
Ortiz: era el día 1o de noviembre de 1931. Fue sustituido por Roberto Fierro. ${ }^{131}$ Ante la situación conflictiva que padecía el gobierno de Fierro, la colonia china de Ciudad Juárez le envió un oficio "patentizando sus respetos y simpatía por la acertada labor administrativa" del citado gobernador; una carta semejante mandó la logia masónica Estrella del Norte, dependiente de la Logia Cosmos de la ciudad de Chihuahua. ${ }^{132}$ Esta última agrupación contaba con varias ramas, de las cuales, la Progreso y la ya mencionada Estrella del Norte estaban integradas exclusivamente por chinos. ${ }^{133}$ En mayo del mismo año, la Unión Fraternal Asociación China de la capital del estado felicitó al jefe de la policía local por las investigaciones efectuadas en torno al asalto de un chino, aunque los presuntos responsables fueron puestos en libertad por falta de méritos. ${ }^{134}$ Los chinos trataban de mantener buenas relaciones con las autoridades.

La Alianza Nacionalista Chihuahuense solicitó al ayuntamiento de la capital del estado que vigilara las condiciones higiénicas de los negocios de extranjeros y su cumplimiento de la ley y que las plazas disponibles en los mercados y lugares bajo control del municipio se destinaran a mexicanos. En la sesión extraordinaria del 22 de enero de 1932, el Ayuntamiento de Chihuahua felicitó a la Alianza "por la noble tarea que se ha echado a cuestas" y aprobó la solicitud en todos sus puntos. Dispuso que autoridades y agentes policiacos fueran informados sobre "esta campaña, para que cooperen patrióticamente y de acuerdo con sus atribuciones". Se comisionó a dos regidores

131 Almada, Diccionario de historia, pp. 383-384.

132 "La colonia china felicita al Sr. Gobernador Fierro", El Heraldo de Chibuabua (30 abr. 1932).

${ }_{133}$ Mendoza, “A la Breve Historia”, http://plandevuelo.mx/site/brevehistoria-de-la-gran-logia-cosmos-del-estado-de-chihuahua/. Consultado el 14 de junio de 2019.

134 "La colonia china felicita al inspector de policía", El Heraldo de Chibuabua (19 mayo 1932). 
para realizar las investigaciones pertinentes. Uno de ellos era Epitacio Orta, ${ }^{135}$ presidente del Comité Antichino número 1.

En febrero de ese mismo año, se recrudeció el conflicto armado en China; la prensa local informó sobre los acontecimientos. ${ }^{136}$ El Comité Central Antichinista, sito en el Distrito Federal, dio a conocer la suspensión de la campaña contra los chinos "en vista de que se encontraban controlados por nacionales los negocios que en varios estados de la República monopolizaban los ciudadanos chinos" y del "injustificado ataque del gobierno imperialista del Japón” a la República China. Consideraban que era "humanitario suspender la campaña antichina en todo el país como una demostración de simpatía hacia el gobierno y pueblo chinos en estos momentos de prueba para esa nacionalidad". Para rematar estas sorprendentes declaraciones, expresaron su solidaridad "con la actitud de la República China”. ${ }^{137}$ El embajador agradeció la suspensión de la campaña antichina, añadiendo que la noticia causaría júbilo en su país. ${ }^{138}$ Sin embargo, unos días después en Chihuahua, el gobernador Roberto Fierro recibió una misiva de Macario Mar, quien representando a la colonia china de Hidalgo del Parral denunciaba que las autoridades municipales habían hecho cobros injustificados a sus connacionales. El oficial mayor de la Secretaría de Gobernación había solicitado al gobierno de Chihuahua que siguiera la recomendación del ejecutivo del estado de Durango: debían aplicarse rigurosamente las disposiciones de migración a los extranjeros para evitar que compitieran con los

135 "Municipalidad de Chihuahua, Ayuntamiento, Sesión extraordinaria del día 22 de enero de 1932", Periódico Oficial del Estado de Chibuabua (13 feb. 1932).

136 "El caos chino", El Heraldo de Chibuabua (7 feb. 1932).

137 “Un Manifiesto del Comité Anti Chino se lanzará pronto", El Heraldo de Chibuabua (26 feb. 1932).

138 "El Embajador de China se muestra muy agradecido", El Heraldo de Chibuabua (25 feb. 1932). 
nacionales. El gobierno del estado, a su vez, remitió la circular al ayuntamiento de Hidalgo del Parral. El presidente municipal de tal localidad citó a los chinos, amenazando a algunos con deportarlos con el pretexto de que su documentación migratoria estaba incompleta. Sin embargo, a cambio de un pago se les dejó en paz. Las cuotas variaron desde 1.20 hasta 21.00 pesos, lo cual despertó las suspicacias de los chinos, pues si se había establecido un gravamen, sería el mismo para todos y "en ningún caso debía ser conforme a la posibilidad o categoría de cada uno". Además, señalaba Mar, algunos habían sido encarcelados. A ningún extranjero de otra nacionalidad se le había solicitado ese pago. Mar adjudicaba los abusos a que varios comerciantes empleados en el ayuntamiento pertenecían a un comité antichino. ${ }^{139}$

Las propuestas sinofóbicas finalmente se formalizaron: el 8 de junio de 1932, la Alianza Nacionalista Chihuahuense solicitó al Congreso del estado leyes semejantes a las de Sonora: establecimiento de guetos para chinos y prohibición tanto de matrimonios como de vida marital de mexicanas con ellos. ${ }^{140}$ Menos de un mes después, Roberto Fierro fue destituido como gobernador por los conflictos que tuvo con la legislatura local, acusado de haber desviado dinero a las campañas del PNR. Lo reemplazó Eduardo Salido. ${ }^{141}$

El 27 de agosto de 1932, en Hidalgo del Parral se formó un Comité Nacionalista apoyado por la Cámara Nacional de Comercio de la localidad, que tenía como objetivos "el mejoramiento de la raza y la defensa de los intereses del comercio y de la industria nacionales contra las maniobras inmorales de capitales y personas extranjeras". ${ }^{142}$ Unas semanas después, Rodrigo M.

139 AGN, DGG, 2.360(6)8027, c. 3, exp. 6, fols. 67, 69 y 70.

140 "Un barrio asiático en cada lugar del estado", El Heraldo de Chibuabua (9 jun. 1932).

141 Almada, Diccionario de historia, pp. 209 y 477.

142 "H. del Parral”, El Heraldo de Chibuabua (31 ago. 1932). 
Quevedo iniciaba una etapa de mayor estabilidad política: ${ }^{143}$ tomó posesión del cargo de gobernador el 4 de octubre de 1932 y su administración terminó el 3 de octubre de $1936 .{ }^{144}$ Sin embargo, las actividades sinofóbicas también continuaron durante su gestión. La XXXV Legislatura del estado, cuyos diputados entraron en funciones el 16 de septiembre de 1932, ${ }^{145}$ decretó el día 15 de diciembre de dicho año la prohibición de matrimonios de "individuos de raza china" con mexicanas, multas y arrestos a las uniones libres entre chinas y mexicanos, y el establecimiento de zonas exclusivas para "individuos de nacionalidad china". ${ }^{146}$ Tres días después, la Alianza Nacionalista Chihuahuense envió un telegrama al presidente de la República solicitando su respaldo a la ley antichina, y Vito Aguirre remitió otro a título personal apelando "a su alto espíritu Nacionalista”, pues la colonia china estaba buscando la derogación de tal ley. ${ }^{147}$ Por su parte, la legación china, por medio de un escrito fechado el 6 de enero de 1933, comunicó su preocupación a la Secretaría de Relaciones Exteriores, pidiendo su intervención, manifestando que tal ley estaba en contra de la Constitución General de la República; la cancillería, a su vez, envió una nota que incluyó la misiva de la legación china a la Secretaría de Gobernación, la cual respondió que se había solicitado al gobernador de Chihuahua información al respecto. El 28 enero, la legación envió otro escrito a Relaciones Exteriores pidiendo informes sobre las leyes antichinas. ${ }^{148}$

El 23 de mayo de 1933, Emilio Chiu, Luis Soon y Juan W. Fong, en representación de la colonia china de la ciudad de

143 АвоIтEs, "De Almeida a Quevedo", pp. 444-445.

144 Almada, Diccionario de historia, p. 437.

145 "Decreto No. 2", Periódico Oficial del Estado de Chibuabua (24 sep. 1932).

146 AGN, DGG, 2.360(6)8027, c. 3, exp. 6, documento sin foliación; GómEZ IZQUIERDO, El movimiento antichino, p. 146.

147 AGN, $A P, A L R$, c. 22, exp.181.7 y 181.7-1, documentos sin foliación.

148 AGN, DGG, 2.360(6)8027, c. 3, exp. 6, documento sin foliación. 
Chihuahua, se apersonaron en la Villa de Aldama para entrevistarse con sus compatriotas, aparentemente para tratar asuntos relacionados con la campaña sinofóbica. ${ }^{149}$ Pero fue aquel día cuando tres chinos fueron atacados sin piedad.

\section{LINCHAMIENTO Y BOICOT}

El 23 de mayo de 1933, dos meretrices hallaron un cadáver en una acequia de la zona de Villa Aldama, población cercana a la ciudad de Chihuahua. ${ }^{150}$ Era el cuerpo de una niña de 13 años, ${ }^{151}$ llamada Obdulia Terrazas; los médicos legistas dictaminaron que había sido violada y estrangulada. Un testigo, Guadalupe Domínguez, afirmó haber visto a la niña en la tienda del chino Fong. Con base en sus declaraciones, se procedió a la detención de los extranjeros Ildefonso Fong y Alfonso Young. El primero era dueño de una tienda y el segundo de una panadería; ambos negocios compartían el mismo edificio. ${ }^{152}$ También detuvieron a Alfonso Ríos, joven panadero mexicano empleado de Young, y al chino José Luis Huie: se les acusó del asesinato y violación de la niña. ${ }^{153}$ Mientras tanto, se corrió la versión de que el cadáver de la niña tenía una herida con forma de trébol en el abdomen y que por ella los chinos le habían chupado la sangre como parte de una ofrenda a sus dioses. ${ }^{154}$ Cerca de las ocho y media de la noche, se juntó una muchedumbre de alrededor de 300; algunas

\footnotetext{
149 AHSTJECH, DM, JPP, SP, causa 73, foja 13.

150 AHSTJECH, DM, JPP, SP, sin número de causa, 23 mayo 1933, fojas 3 y 7.

151 "Tres chinos linchados anoche en Villa Aldama”, La Voz de Chibuabua (24 mayo 1933).

152 AHSTJECH, DM, JPP, SP, sin número de causa, fojas 3, 8-9, 11, 13, $16, \mathrm{y} 18$.

153 "Tres chinos linchados anoche en Villa Aldama", La Voz de Chibuabua (24 mayo 1933); AHSTJECH, DM, JPP, SP, causa 63, fojas 13 y 14.

154 AHSTJECH, DM, JPP, SP, causa 63, foja 37; "Varias personas fueron detenidas por los linchamientos de Aldama", La Voz de Chibuahua (25 mayo 1933).
} 
personas de la multitud exigieron al alcalde que les entregara a los tres chinos para ajusticiarlos. Diversas autoridades se dirigieron a los manifestantes tratando de tranquilizarlos, asegurándoles que se haría justicia. El comerciante Federico Cuilty replicó a gritos que eso no era verdad; de no hacerse justicia de inmediato, vociferó, al día siguiente los chinos comprarían al juez por 1000 pesos. En la turba destacaba por sus alaridos otro comerciante, José Luis Hermosillo: se encontraba ebrio. Finalmente, la multitud irrumpió en la cárcel y los tres chinos fueron asesinados a golpes. ${ }^{155}$ El detenido mexicano ya había sido puesto en libertad. ${ }^{156}$ La noticia fue publicada en la prensa internacional. ${ }^{157}$

Al día siguiente, los sinófobos decidieron que era el momento de embestir a los negocios chinos. Aunque La Voz de Chibuabua negó que los crímenes de Aldama tuvieran relación con tal decisión, es de suponerse que los sinófobos presumieron que el asesinato de la niña levantaría animosidad contra los chinos entre el resto de la población. En la ciudad de Chihuahua, a las puertas de sus restaurantes, puestos de verduras ${ }^{158} \mathrm{y}$ comercios, se instalaron con garrotes los autodenominados "guardias verdes" para impedir la entrada de clientes. En el frente de los negocios chinos pusieron rótulos que trataban de disuadir a los mexicanos de comprar en dichos lugares. "El dinero que

155 AHSTJECH, DM, JPP, SP, causa 63, fojas 2, 5, 7, 9-10, 11, 18, 34, 37, 39, 41, 249, 264-67 y 273. La ocupación de Cuilty se investigó en el Quinto Censo de Población 1930 en Ancestry.mx, https://search.ancestry.mx/search/ db.aspx?dbid=1771. Consultado el 20 de mayo de 2019.

156 "Varias personas fueron detenidas por los linchamientos de Aldama", La Voz de Chibuabua (25 mayo 1933).

157 "Mexicans Lynch Three Chinese in Boycott Drive", Chicago Tribune (25 mayo 1933); "Chinese Lynched Boycott Riots in Mexico", The Singapore Free Press and Mercantile Advertiser (26 mayo 1933); "Chinese are Lynched in México", Winnipeg Free Press (25 mayo 1933).

158 "El Boycot contra los chinos ocasionó el alza inmoderada en todos los comestibles", La Voz de Chibuabua (25 mayo 1933). La prensa internacional publicó sobre el boicot en las mismas notas en que dio a conocer el linchamiento de Aldama. 
gaste aquí no beneficia a nadie", "Sea mexicano, no compre aquí", "Haga patria ayudando a los suyos", eran las leyendas. Amas de casa manifestaron su descontento, pues preferían los comercios chinos por los precios y facilidades de pago y les fue impedido el acceso. Algunos "guardias verdes" incluso trataron de evitar que los chinos salieran de sus viviendas. La policía logró que los guardias desistieran de esto último y también que abandonaran sus garrotes, autorizándoles solamente a usar la persuasión. ${ }^{159} \mathrm{~A}$ pesar de la intimidación, algunas personas hicieron sus compras, aunque los negocios chinos cerraron a las diez de la mañana. Los "guardias verdes" continuaron apostados hasta la noche. Asimismo, los sinófobos no permitieron que los hortelanos chinos de los alrededores de la ciudad ingresaran a los mercados de La Reformita y de la calle Venustiano Carranza. ${ }^{160}$ Además, los chinos de La Junta y zona aledaña no entraron a la ciudad a vender sus verduras. Todo lo anterior provocó aglomeraciones de consumidores, gran escasez de verduras en la ciudad ${ }^{161}$ y aumento de precio en los comestibles. ${ }^{162}$

Juan Fong, representante de la colonia china de la ciudad de Chihuahua, acompañado por el cónsul de Estados Unidos, se entrevistó con el secretario general del gobierno del estado. Éste reiteró la voluntad del ejecutivo de hacer cumplir las leyes y respetar las garantías de las personas de cualquier nacionalidad. Fong también dio aviso a la legación. ${ }^{163}$ Tanto ésta como la colonia china de la ciudad de Chihuahua informaron de los

159 "Obligaron a cerrar el comercio de los chinos los nacionalistas", El Heraldo de Chibuabua (25 mayo 1933).

160 "El Boycot contra los chinos ocasionó el alza inmoderada en todos los comestibles”, La Voz de Chibuabua (25 mayo 1933).

161 "Obligaron a cerrar el comercio de los chinos los nacionalistas", El Heraldo de Chibuahua (25 mayo 1933).

${ }^{162}$ El Boycot contra los chinos ocasionó el alza inmoderada en todos los comestibles", La Voz de Chibuabua (25 mayo 1933).

163 "Obligaron a cerrar el comercio de los chinos los nacionalistas", El Heraldo de Chibuabua (25 mayo 1933). 
hechos a la cancillería mexicana, la cual a su vez lo comunicó al gobernador de Chihuahua. De acuerdo con el ministro chino, las autoridades locales y la policía habían cooperado con los antichinos. ${ }^{164}$

En el segundo día de la campaña contra los negocios chinos se presentaron algunos incidentes: la profesora Margarita $\mathrm{H}$. Campos protestó por habérsele impedido el acceso a un comercio chino y un agente de la policía trató de convencerla de que desistiera. Así, "el asunto se fue agriando y tomó dimensiones de escándalo", siendo la profesora conducida a la inspección de policía, donde fue liberada después de haberse comunicado con "altas personalidades del Gobierno del Estado". Un hombre identificado como José María Obeso quedó detenido por "ultrajes a la señora de Campos". ${ }^{165}$ Actos de violencia llevaron al arresto de los guardias antichinos Prisciliano Segura, José Espinoza y Carlos H. Valderrama, por haber lesionado al joven Alonso López, quien trató de defender a una señorita que pretendía hacer sus compras. ${ }^{166}$ Otros "guardias verdes" también fueron detenidos por ese mismo incidente. Después de amonestárseles, a todos se les dejó en libertad. ${ }^{167}$

También se detuvo al presidente del Círculo Fraternal del Instituto Científico y Literario, Carlos Velarde, quien al frente de un grupo de estudiantes manifestó su oposición a la campaña sinofóbica quitando unos rótulos antichinos instalados frente a un negocio. Fue puesto en libertad en cuanto llegó a la Inspección de policía; al joven Velarde lo acompañó el grupo

164 AGN, DGG, 2.360(6)8027, c. 3, exp. 6, documentos sin foliación.

165 "El gobierno dará garantías y hará que se respeten las leyes", El Heraldo de Chibuabua (26 mayo 1933).

166 "Comerciantes extranjeros entrevistan al gobernador a favor de los asiáticos”, El Heraldo de Chibuabua (27 mayo 1933).

167 "Fueron remitidos a la comandancia diez guardias nacionalistas", La Voz de Chibuabua (27 mayo 1933). 
de estudiantes que lideraba. ${ }^{168}$ Gustavo Murillo, secretario del Círculo Fraternal, junto con Carlos Velarde, entregaron a $\mathrm{La}$ Voz de Chibuabua un escrito en el cual se declaraban nacionalistas, pero opuestos al boicot contra los chinos, repudiándolo por restringir la libertad, pues tales actos "no sólo lesionan los intereses de los chinos, sino también el libre arbitrio de los compradores mexicanos" ${ }^{169}$ Se hizo patente una vez más el peso de la preferencia de los consumidores por los negocios chinos.

En Ciudad Juárez también se intentó el boicot, aunque con la peculiaridad de que los antichinos atravesaron la bandera mexicana en la entrada de los locales chinos para impedir el ingreso de clientes. La policía, por orden del presidente municipal Jesús Quevedo, ${ }^{170}$ hermano del gobernador del estado, ${ }^{171}$ recogió las banderas por considerar que su uso para esos fines era un atropello a la insignia. ${ }^{172}$ Además, las autoridades obligaron al comerciante Jesús V. Carbajal ${ }^{173}$ a interrumpir su discurso antichino pronunciado en la Plaza de Armas; pocas personas siguieron el llamado de los sinófobos. ${ }^{174} \mathrm{La}$ Unión Fraternal de la Colonia China de Ciudad Juárez envió un escrito al secretario de Gobernación informándole "que se pretende impedírsenos por medio de la violencia, el libre ejercicio del comercio y la industria llevando a cabo actos de boicotaje contra nuestros

168 "El gobierno dará garantías y hará que se respeten las leyes", El Heraldo de Chibuabua (26 mayo 1933).

169 “La grey estudiantil censura el boycot”, La Voz de Chibuabua (26 mayo 1933).

170 "En Juárez no secundaron el boycot”, La Voz de Chibuabua (25 mayo 1933); Schiavone Camacho, Chinese Mexicans, p. 99.

171 Wasserman, Persistent Oligarchs, pp. 101 y 134.

172 "En Juárez no secundaron el boycot", La Voz de Chibuahua (25 mayo 1933).

173 Su ocupación se investigó en el Quinto Censo de Población 1930 en Ancestry.mx, https://search.ancestry.mx/search/db.aspx?dbid=1771, consultado el 20 de mayo de 2019.

174 "Fue iniciado por la Liga Nacionalista de Ciudad Juárez", El Continental (24 mayo 1933); Schiavone Camacho, Chinese Mexicans, p. 99. 
establecimientos". ${ }^{175}$ La Unión también se dirigió a la presidencia de la república, al gobierno del estado, a la presidencia municipal y al Ministerio de China en México para pedir garantías. ${ }^{176}$

En la ciudad de Chihuahua, un grupo de 30 extranjeros, entre ellos los cónsules norteamericano y francés, se entrevistaron con el gobernador Rodrigo M. Quevedo para pedir protección para los comerciantes chinos. El jefe del ejecutivo estatal dio amplias garantías de que haría respetar los derechos de los extranjeros; además, prometió investigar la orden de desalojar algunos locales rentados por chinos en el mercado La Reforma, dada por el ayuntamiento de Chihuahua. ${ }^{177} \mathrm{La}$ orden fue suspendida. ${ }^{178}$

Por otra parte, una comisión de la Cámara Nacional de Comercio local, integrada por Ricardo Hernández, Carlos A. Nieto e Ignacio Chávez, también se entrevistó con el gobernador, entregando una petición para poner fin al hostigamiento a los negociantes chinos, ya que también el comercio mayorista se había visto perjudicado, pues no se había podido cobrar la mercancía a crédito. ${ }^{179}$ Por un lado, los mayoristas defendían a sus clientes chinos para salvaguardar sus propios intereses, y por el otro, pequeños comerciantes mexicanos pretendían proteger los suyos atacando a los negocios chinos.

Otra voz se sumó en contra del boicot, pero con distintos argumentos. En un artículo de El Heraldo de Chibuahua, Fernando Illades pretendía defender a la raza mexicana "que por

\footnotetext{
175 AGN, DGG, 2.360(6)8027, c. 3, exp. 6, documento sin foliación.

176 "Fue iniciado por la Liga Nacionalista de Ciudad Juárez", El Continental (24 mayo 1933); AGN, DGG, 2.360(6)8027, c. 3, exp. 6, documento sin foliación.

177 "Comerciantes extranjeros entrevistan al gobernador a favor de los asiáticos”, El Heraldo de Chibuahua (27 mayo 1933).

178 "Los puestos de fritangas no pueden estar dentro del mercado", El Heraldo de Chibuabua (2 jun. 1933).

179 "El gobierno actuará enérgicamente en el caso de los antichinos", El Heraldo de Chibuabua (28 mayo 1933).
} 
unos cuantos inconscientes está desmereciendo ante el mundo entero por ensañarse con unos extranjeros hoy por hoy los más oprimidos y retrasados dentro del concierto de las naciones civilizadas". Continuaba criticando la campaña antichina por considerarla indigna de los descendientes del Cid Campeador y del "emperador que supo sonreír ante el martirio". Había que evitar "el espectáculo vergonzante de ponernos en contra de quien no puede defenderse". Recomendaba ayudar a "esos pobres seres extranjeros mientras se porten bien y trabajen con honradez". Pero aclaraba que esa ayuda no debía incluir mezclarse con ellos. ${ }^{180}$

El 28 de mayo de 1933 ya no hubo vigilancia de los guardias verdes. La policía los había retirado del frente de los negocios chinos, custodiándolos continuamente. ${ }^{181}$ Las autoridades amonestaron a los líderes antichinos, entre ellos a Vito Aguirre, quien según el periódico La Voz de Chibuabua era apodado "el Hitler de Chihuahua" y a sus seguidores se les conocía como "los nazis", por autodenominarse nacionalistas. Enrique González Flores, secretario general del gobierno del estado, reiteró que se daba "toda clase de garantías a las personas que lo necesiten cualquiera que sea su nacionalidad”. La Voz lamentaba las notas de la prensa de El Paso, Tejas, en las cuales criticaban que los mexicanos se quejaran por ser discriminados en Estados Unidos mientras en México se perseguía a los chinos. ${ }^{182}$

Los antichinos mochitecos dieron la medida del fracaso del boicot sinofóbico en Chihuahua. El 2 de junio de 1933, el Comité Nacionalista Pro-Raza de Los Mochis, Sinaloa, acordó convocar a los organismos nacionalistas del país a manifestarse en solidaridad con los antichinos de Chihuahua, "en virtud de

\footnotetext{
180 "Por la defensa de la raza", El Heraldo de Chibuabua (28 mayo 1933).

181 "La campaña en contra de los chinos cesó", El Heraldo de Chibuabua (29 mayo 1933).

182 "Ya no pesa sobre el comercio chino la ley del garrote", La Voz de Chibuabua (26 mayo 1933).
} 
la inconsecuente y antipatriótica campaña que se ha desatado en contra de las actividades puestas en práctica por nuestros connacionales del vecino Estado de Chihuahua". ${ }^{183}$ En Sonora y Sinaloa se había logrado la expulsión de millares de chinos, ${ }^{184}$ pero el apoyo a los sinófobos chihuahuenses tuvo que buscarse a nivel nacional, pues no lo habían encontrado en su propia tierra.

\section{CONCLUSIONES}

Los chinos establecieron vínculos con variados grupos de mexicanos. Para consumidores y empresarios, la presencia china se tradujo en beneficios económicos. Funcionarios públicos de diversas dependencias llevaban buena relación con estos extranjeros y algunos chinos pertenecían a logias masónicas reconocidas por sus pares mexicanos. Algunos de ellos estaban casados o vivían en unión libre con mexicanas. En estas condiciones, quienes se consideraban perjudicados por los negocios chinos trataron de deshacerse de sus competidores organizando distintos comités que, con argumentos nacionalistas, intentaron conseguir el apoyo de la población. Pero los comités antichinos sufrieron críticas y descalificaciones en la prensa por mostrarse nacionalistas cuando, en realidad, pretendían proteger sus intereses económicos y porque sus acciones se consideraban indignas de los mexicanos. Cuando atacaban a los chinos, éstos publicaban mensajes en los periódicos para dar a conocer su versión de los hechos, tratando de conservar apoyo entre la comunidad. También los chinos se encargaban de enviar comunicados a su legación y a las autoridades federales y estatales. Los resultados de tales mensajes fueron favorables a sus remitentes. Ante las maniobras antichinas, los altos mandos federales reconvenían al ejecutivo estatal. Dada la inestabilidad política de los gobiernos

183 AGN, DGG, 2.360(6)8027, c. 3, exp. 6, documento sin foliación.

184 Chang, Chino, p. 13. 
chihuahuenses, las reprimendas eran exitosas: el gobierno del estado se encargaba de detener las acciones sinofóbicas. Similar fue la tónica respecto del congreso local; aunque se aprobaron leyes antichinas, éstas no entraron en vigor: nunca se publicaron en el periódico oficial. Los sinófobos no lograron que ninguna instancia gubernamental tomara medidas drásticas y duraderas contra los chinos.

El boicot en las dos ciudades más pobladas de la entidad exhibió las particularidades del movimiento antichino en Chihuahua. De forma oportunista, los antichinos quisieron aprovechar el odio manifestado contra unos presuntos asesinos para extenderlo al resto de los chinos, a quienes ya tenían tiempo presentando como enemigos de la nación. El ardid no funcionó. Los estudiantes del Instituto Científico y Literario se movilizaron en su contra, a lo que se añadió el enfado de empresarios mayoristas, el descontento por la escasez de verduras y el aumento de los precios de los víveres, y destacadamente, la resistencia de los clientes de comercios chinos. A diferencia del caso de Sonora, donde los chinos fueron un factor de unidad debido a que todas las clases los odiaban ${ }^{185}$, en Chihuahua los antichinos no sumaron a otros grupos sociales. Por el contrario, los sinófobos lograron unir a distintos grupos de chihuahuenses, pero en su contra. El resultado del boicot fue que la legitimidad de la presencia china se vio fortalecida. Aunque opositores al antichinismo declararon estar en contra de la miscegenación, difícilmente habrían tomado medidas para evitarla: ello implicaba arremeter contra los chinos, y habían reconocido que éstos estaban siendo atacados injustamente y en perjuicio de chihuahuenses.

Ante las acciones sinofóbicas, hubo respuestas que apelaron al nacionalismo, según lo entendían distintos chihuahuenses: estudiantes y editorialistas públicamente reprobaron las acciones antichinas, manifestándose, no en contra del nacionalismo, sino

185 Delgado, Making the Chinese Mexican, p. 111. 
de la versión sinofóbica del mismo. El Correo de Chibuabua consideraba que el antichinismo, más que ser nacionalista, perjudicaba a la nación: se preocupaba por la imagen que daban los disturbios a nivel internacional. Compartía esta preocupación el editorialista Fernando Illades, quien, aunque convencido de la inferioridad de los chinos, llamaba a tener consideración por ellos; era indigno de los mexicanos maltratarlos. Por su parte, los estudiantes del Instituto Científico y Literario manifestaron su nacionalismo oponiéndose a que se restringiera a sus compatriotas la libertad para efectuar compras donde lo consideraran conveniente. Según Knight, el nacionalismo económico popular es equivalente a xenofobia; en él subyacen antipatías socioeconómicas y culturales. ${ }^{186} \mathrm{La}$ acción nacionalista de los estudiantes tenía un origen económico, pero no se mostró como xenofobia: se enfrentaron a los sinófobos por limitar los derechos de los mexicanos.

Como lo han mostrado, entre otros, Knight, ${ }^{187}$ Rénique $^{188}$ y Chang, ${ }^{189}$ el movimiento antichino tuvo un papel destacado en la formación del nacionalismo posrevolucionario. En el caso de Chihuahua, el antichinismo provocó diversas manifestaciones de nacionalismo, las cuales no confluyeron por su odio a los chinos, sino por su oposición al movimiento sinofóbico.

\section{SIGLAS Y REFERENCIAS}

AGN, APA, LR Archivo General de la Nación, Archivo Presidentes, Abelardo L. Rodríguez, Ciudad de México, México.

AGN, DGG Archivo General de la Nación, Dirección General de Gobierno, Ciudad de México, México.

AHMCH, $R, P \quad$ Archivo Histórico del Municipio de Chihuahua, fondo Reconstrucción, sección Presidencia, Chihuahua, México.

186 KNIGHT, Repensar la Revolución mexicana, vol. II, p. 26.

187 KNIGHT, Repensar la Revolución mexicana, vol. II, pp. 49-108.

188 Rénique, “Anti-Chinese Racism”, 91-140.

189 Chang, Chino. 
AHMCH, $R, S$ Archivo Histórico del Municipio de Chihuahua, fondo Reconstrucción, sección Secretaría, Chihuahua, México.

AHMHP, E Archivo Histórico del Municipio de Hidalgo del Parral, Extranjeros, Chihuahua, México.

AHSTJECH, DM, JPP, SP Archivo Histórico del Supremo Tribunal de Justicia del Estado de Chihuahua, sección Distrito Morelos, subsección Juzgado Primero de lo Penal, Chihuahua, México.

DGCP Dirección General de Crónica Parlamentaria, Cámara de Diputados, México.

DSUSA, OH, PRFRUS, APC Department of State of the United States of America, Office of the Historian, Papers Relating to The Foreign Relations of the United States, with the Address of the President to Congress, Estados Unidos.

INEGI Instituto Nacional de Estadística, Geografía e Informática, México.

Aвогтеs, Luis, "De Almeida a Quevedo: lucha política en Chihuahua (19271932)", en Actas del Segundo Congreso de Historia Regional Comparada, Ciudad Juárez, Chihuahua, Universidad Autónoma de Ciudad Juárez, 1990.

Almada, Francisco R., Diccionario de historia, geografía y biografía chibuabuenses, Ciudad Juárez, Universidad Autónoma de Chihuahua, 1968.

Avitia Hernández, Antonio, El país de las hojas sueltas, México, sin editorial, 2016, https://www.bibliotecas.tv/avitia/el_pais_de_las_hojas_sueltas/el_pais_ de_las_hojas_sueltas_Tomo_III.pdf. Consultado el 30 de mayo de 2019.

Botton Beja, Flora, "La persecusión de los chinos en México", en Estudios de Asia y África, XLIII: 2 (2008), pp. 477-486.

Brondo WhitT, Encarnación, Sucesos notables de la Revolución en el estado de Chibuahua, Chihuahua, Gobierno del estado de Chihuahua, 2005.

Buchenau, Jürgen, "Small Numbers, Great Impact: Mexico and Its Immigrants, 1821-1973”, en Journal of American Ethnic History, 20: 3 (2001), pp. 23-49.

Chang, Jason Oliver, Chino, Champaign, University of Illinois Press, 2017.

Chou, Diego, Los chinos en Hispanoamérica, en serie Cuadernos de Ciencias Sociales 124, San José, flacso Costa Rica, 2002. 
CoTT, Kennett, “Mexican Diplomacy and the Chinese Issue, 1876-1910”, en The Hispanic American Historical Review, 67: 1 (1987), pp. 63-85.

Davis, Diane E. (ed.), Political Power and Social Theory, vol. 14, Amsterdam, Emerald Group Publishing Limited, 2001.

Delgado, Grace, Making the Chinese Mexican, Stanford, Stanford University Press, 2012.

Delgado, Marco Antonio, Romance histórico villista, Chihuahua, México, edición de autor, 1975.

Gómez Izquierdo, José Jorge, El movimiento antichino en México (18711934), México, Instituto Nacional de Antropología e Historia, 1991.

González Navarro, Moisés, Los extranjeros en México y los mexicanos en el extranjero, 1821-1970, vol. II, 1867-1910, México, El Colegio de México, 1994.

González Navarro, Moisés, Los extranjeros en México y los mexicanos en el extranjero, 1821-1970, vol. III, 1910-1970, México, El Colegio de México, 1994.

Ham Chande, Roberto, "La migración china hacia México a través del Registro Nacional de Extranjeros”, en Ota Mishima (coord.), 1997, pp. 167-188.

Hu DeHart, Evelyn, "Immigrants to a Developing Society: The Chinese in Northern Mexico, 1875-1932”, en Journal of Arizona History, 21: 3 (1980), pp. 275-312.

KIM, Mee-Ae, “Immigrants, Workers, Pioneers: The Chinese and Mexican Colonization Efforts, 1890-1930”, tesis de doctorado en historia, Washington, Washington State University, 2000.

Knight, Alan, Repensar la Revolución mexicana, México, El Colegio de México, 2013.

LLOYD, Jane-Dale, El proceso de modernización capitalista en el noroeste de Chibuabua, 1880-1910, México, Universidad Iberoamericana, 1987.

Lloyd, Jane-Dale, Cinco ensayos sobre cultura material de rancheros y medieros del noroeste de Chibuahua, 1886-1910, México, Universidad Iberoamericana, 2001. 
Mendoza, Jesús, “A la Breve Historia de la Benemérita y Centenaria Muy Respetable Gran Logia 'Cosmos' de Estado de Chihuahua”, en http://alphasigloxxi.org/historia_gran_logia.html. Consultado el 14 de junio de 2019.

Morris, Stephen D., "Reforming the Nation: Mexican Nationalism in Context”, en Journal of Latin American Studies, 31: 2 (1999), pp. 363-397.

Ota Mishima, María Elena (coord.), Destino México, México, El Colegio de México, 1997.

Rénique, Gerardo, "Anti-Chinese Racism, Nationalism and State Formation in Post-Revolutionary Mexico, 1920s-1930s”, en DAvis (ed.), 2001, pp. 91-140.

Romero, Robert Chao, “'El destierro de los chinos': Popular Perspectives on Chinese-Mexican Intermarriage in the Early Twentieth Century", en Aztlán: A Journal of Chicano Studies, 32: 1 (2007), pp. 113-144.

Romero, Robert Chao, The Chinese in Mexico, 1882-1940, Tucson, Arizona, University of Arizona Press, 2010.

Schiavone Camacho, Julia María, "Crossing Boundaries, Claiming a Homeland: The Mexican Chinese Transpacific Journey to Becoming Mexican, 1930s-1960s", en Pacific Historical Review, 78: 4 (2009), pp. 545-577.

Schiavone Camacho, Julia María, Chinese Mexicans, Chapel Hill, University of North Carolina Press, 2012.

Treviño, Rangel, Javier, "Racismo y nación: comunidades imaginadas en México”, en Estudios Sociológicos, $26: 78$ (2008), pp. 669-694.

TreviÑo, RAngel, Javier, “Los 'hijos del cielo' en el infierno: un reporte sobre el racismo hacia las comunidades chinas en México, 1880-1930", en Foro Internacional, 45: 3 (2005), pp. 409-444.

Wasserman, Mark, Persistent Oligarchs: Elites and Politics in Chibuabua, Mexico 1910-1940, Durham, Duke University Press, 1993.

Wu, Gen-hua, Chinos en México y Guatemala, Taipei, Overseas Publishing Co, 1989. 